\title{
VIII Congresso da Sociedade Brasileira de Radioterapia
}

VI Jornada de Física Médica

IV Encontro de Enfermeiros Oncologistas em Radioterapia

III Encontro de Técnicos em Radioterapia da SBRT

DATA: 26 a 28 de outubro de 2006

LOCAL: Hotel Atlântico Búzios, Búzios - RJ

\section{Resumos}




\section{Amifostina reduz ativação da MAPK p38} durante a sinalização da apoptose em células da medula óssea irradiadas in vivo

\author{
Segreto HRC, Carvalho PB, Egami ME, Giordani AJ, Oshima CTF, Silva MRR, \\ Teixeira VPC, Segreto RA \\ UNIFESP/HSP - São Paulo - (SP)
}

Introdução: O papel da MAPK p38, na sinalização da apoptose ou na sobrevivência, varia dependendo do tipo de célula, estágio maturativo e agente indutor. Objetivos: Avaliar a expressão e a ativação da MAPK p38 e seu papel na sobrevivência ou apoptose das células da medula óssea irradiadas in vivo com ou sem amifostina (Ami). Métodos: Utilizou-se 56 camundongos C57BL, sendo: GIa - SF IP; GIb - Ami IP; GIIa - SF IP + 7Gy e GIIb - Ami IP $30 \mathrm{~min}$ antes de $7 \mathrm{~Gy}$. Sacrifício: 30min, 1h, $2 \mathrm{~h}$ e $4 \mathrm{~h}$ após tratamento. Coloração com Giemsa; imunoistoquímica (IHQ) para caspase 3 clivada, p38 e p38 fosforilado (p-p38); e microscopia eletrônica (ME). Resultados: GIIb - melhor preservação das linhagens celulares e menor ocorrência de apoptose do que GIIa; forte imunoexpressão da p38 em granulócitos $(\mathrm{G})$ e megacariócitos (M) no núcleo e/ou citoplasma em todos os grupos; expressão tênue da p-p38 em G e M em GIa e GIb; forte imunoexpressão da p-p38 em GIIa em 1h, 2h e 4h após 7Gy; expressão tênue da p-p38 em G e M em GIIb. Conclusões: Amifostina protegeu as células da mo da apoptose radioinduzida; a p38 é expressa em G e M da mo em condiçôes fisiológicas; tanto a Ami quanto a radiação não alteraram a expressão da p38 nem sua localização subcelular; a radiação induziu a ativação da p38 e a presença de Ami reduziu esta ativação; a ativação da p38 está envolvida na sinalização da morte celular. 1

\section{Toxicidade urinária tardia em pacientes com carcinoma de próstata tratados com radioterapia conformada}

\author{
Nakamura RA, Monti CR, Castilho LN, Trevisan FA, Kawakami NS, Borges LF \\ Instituto do Radium de Campinas - Campinas - (SP)
}

Introdução: Qualidade de vida é um importante objetivo no tratamento dos pacientes com carcinoma de próstata. Identificar fatores prognósticos associados à toxicidade urinária tardia (TUT) após radioterapia conformada (3DCRT) nesses pacientes pode auxiliar na redução das complicaçōes associadas ao tratamento. Objetivos: Reportar TUT após 3DCRT em pacientes com câncer de próstata e identificar fatores prognósticos associados à TUT. Métodos: De jul/1997 a jan/2002, 285 pacientes com câncer de próstata localizado foram submetidos a 3DCRT e foram analisados retrospectivamente. Trinta e sete (13\%) pacientes apresentavam ressecção transuretral de próstata (RTU) pré-3DCRT. 3DCRT em pelve e em vesículas seminais foram realizadas em $50(17,5 \%)$ e 244 (85,6\%) pacientes, respectivamente. A dose mediana em próstata foi 79,2Gy $(70,2-84,6)$. Resultados: Em seguimento mediano de 53,6 meses (3,6-95,3 meses), sobrevida atuarial livre TUT graus $2-3$ em cinco anos foi $91,1 \%$. Sete e quinze pacientes tiveram TUT graus 2 e 3 , respectivamente. Dois e três pacientes tiveram cistite graus $2 \mathrm{e} 3$, respectivamente. Um e oito pacientes tiveram retenção urinária graus 2 e 3 , respectivamente. Sete pacientes tiveram hematúria grau 3. Quatro pacientes tiveram incontinência urinária grau 2. RTU pré-3DCRT e dose de radiação $>70$ Gy em $30 \%$ volume de bexiga resultou em mais TUT graus $2-3$ ( $\mathrm{p}=0,0002$ e $\mathrm{p}=0,0264$, respectivamente). Conclusóes: $\mathrm{O}$ estudo sugere que restringir a dose de radiaçáo $=70 \mathrm{~Gy}$ em $30 \%$ volume de bexiga à tomografia de planejamento pode reduzir TUT, e a existência de RTU pré-3DCRT pode sinalizar um maior risco TUT graus 2-3.
Aumento do controle do carcinoma de próstata com irradiação de vesículas seminais em pacientes de risco intermediário e de alto risco

Nakamura RA, Monti CR, Castilho LN, Trevisan FA, Borges LF, Kawakami NS Instituto do Radium de Campinas - Campinas - (SP)

Introdução: $\mathrm{O}$ risco de envolvimento de vesículas seminais (vvss) em pacientes com câncer de próstata pode ser estimado, pela associação do valor de Gleason, estágio clínico T e valor do PSA total. De acordo com o risco, as vvss devem ser tratadas. Objetivos: Reportar os benefícios da irradiação de vvss em pacientes com câncer de próstata de baixo risco (BR), de risco intermediário (RI) e de alto risco (AR). Métodos: De jul/ 1997 a jan/2002, 285 pacientes com câncer de próstata foram tratados com radioterapia conformada e foram analisados retrospectivamente. Os pacientes foram divididos em $\mathrm{BR}(\mathrm{PSA}<10 \mathrm{ng} / \mathrm{ml}, \leq \mathrm{T} 2 \mathrm{a}$, valor de Gleason $\leq 6)$ : 95 pacientes; RI (PSA $\geq 10<20 \mathrm{ng} / \mathrm{ml}$, T2b-T2c ou valor de Gleason=7): 66 pacientes; AR (PSA $\geq 20 \mathrm{ng} / \mathrm{ml}$, T3 e/ou valor de Gleason $>7$, ou dois critérios $\mathrm{RI}$ ): 121 pacientes. Resultados: Em seguimento mediano de 53,6 meses (3,6-95,3 meses), a sobrevida atuarial global em 5 anos (SG) para os pacientes que receberam ou não radioterapia de vvss foi $87,5 \%$ e $69,6 \%$, respectivamente $(p=0,0125)$. No BR, a irradiação de vvss não aumentou o controle do câncer de próstata. No RI, SG para pacientes submetidos ou não à irradiação vvss foi $87,8 \%$ e 55,6\%, respectivamente $(\mathrm{p}=0,0034)$, e a sobrevida atuarial livre de recidiva bioquímica em 5 anos (SLRB) foi $77,6 \%$ e $40,4 \%$, respectivamente $(\mathrm{p}=0,0301)$. No $\mathrm{AR}, \mathrm{SLRB}$ para pacientes submetidos ou não à radioterapia vvss foi $66,3 \%$ e $35,7 \%$, respectivamente $(p=0,0040)$. A irradiação de vvss não aumentou a toxicidade urinária ou retal tardias. Conclusóes: $\mathrm{O}$ estudo sugere que a irradiação de vvss aumenta SG e SLRB no RI e AR. Irradiação de vvss no BR não aumenta o controle da doença.

2

Estudo da viabilidade de realização de braquiterapia de alta taxa de dose em próstata com utilização de anestesia local

\section{Pellizzon ACA, Guimarães F, Salvajoli JV, Novaes PE, Sanches R, Maia Maria, Fogaroli R, Hanriot R, Guedes D Centro de Tratamento e Pesquisa Hospital do Câncer - São Paulo - (SP)}

Introdução: A braquiterapia de próstata (BQT) é usualmente realizada sob anestesia geral ou raquideana; porém, a realização da BQT temporária (alta taxa de dose - ATD) com anestesia local passa a ser uma realidade em nosso meio. Foi detalhada a técnica de realização da BQT-ATD com anestesia local e sedação consciente, o que permite a sua realização em regime ambulatorial. Métodos: Dez implantes realizados consecutivamente em 5 pacientes apresentando câncer de próstata local, com risco intermediário ou alto para falha bioquímica, foram tratados em um protocolo institucional combinando BQT-ATD e radioterapia conformada hipofracionada (RT3Dh). O esquema de tratamento utilizado foi realização de dois implantes, com intervalo semanal, onde duas fraçóes de 7,5Gy foram administradas com intervalo mínimo de 6 horas, totalizando 30Gy. RT3Dh consistiu de 45 administrados em 15 fraçóes, em 6/8 campos. Resultados: A idade dos pacientes variou de 46 a 69 anos (mediana 62 anos) e os volumes prostáticos de $25 \mathrm{cc}$ a $48 \mathrm{cc}$ (mediana $33 \mathrm{cc}$ ). A quantidade de lidocaína empregada variou de $250 \mathrm{mg}$ a $500 \mathrm{mg}$ (mediana $300 \mathrm{mg}$ ), sendo essa variação dependente da tolerância do paciente. O tempo de realização do implante variou de $50 \mathrm{~min}$ a $90 \mathrm{~min}$, sendo que o tempo para realização da anestesia variou de $15 \mathrm{~min}$ a $25 \mathrm{~min}$. Conclusóes: A BQT-ATD com anestesia local é factível, eficiente e pode ser realizada em regime ambulatorial, otimizando a ocupação dos leitos hospitalares e pessoal envolvido no tratamento, provavelmente contribuindo para a sua realização em larga escala. 


\section{Nanotecnologia: perspectivas de aplicações em oncologia}

Fernandes MAR1'-5, Tada A' ${ }^{2}$ Maio MF ${ }^{2}$ 1 Serviço de Radioterapia da Faculdade de Medicina da UNESP de Botucatu - SP ${ }^{2}$ Centro Universitário Católico Auxilium - UniSalesiano - Araçatuba, ${ }^{3}$ Universidade Paulista - UNIP - Araçatuba - SP , ${ }^{4}$ CETEA - Centro de Ensino e Tecnologia de Araçatuba - SP, ${ }^{5}$ Nucleata - Dosimetria das Radiações - Araçatuba - SP

O trabalho pretende ilustrar o caráter interdisciplinar da nanotecnologia e realçar a necessidade de maior abordagem dos tópicos da nanociência nos cursos de graduação, visando a despertar o interesse para pesquisas que mostram importantes contribuiçōes na área oncológica. A nanotecnologia representa a habilidade de manipulação de átomos numa dimensão da ordem de $0,1 \mathrm{~nm}$ a $100 \mathrm{~nm}$, objetivando-se obterem novas e maiores estruturas reorganizadas. A nanociência envolve conhecimentos de física, engenharia, química, matemática, biologia, eletrônica, computação, dentre outras disciplinas. Os nanomateriais desenvolvidos nas últimas décadas revolucionaram importantes conceitos de engenharia. Os avanços da nanotecnologia têm contribuído para a obtenção de nanomoléculas utilizadas em bioengenharia e biologia molecular. Os primeiros resultados das aplicaçôes biomédicas da nanotecnologia se apresentam como mais uma alternativa para o diagnóstico e o tratamento do câncer. $\mathrm{O}$ uso de nanopartículas (NPM) magnéticas biocompatíveis, para a identificação de células cancerígenas, aparece como droga de potencial quimioterápico com excelente razão terapêutica. As NPM são catalizadoras de magnetohipertermia e quando associadas a anticorpos monoclonais apresentam maior sensibilidade às células tumorais, reafirmando os exames de ressonância nuclear magnética utilizados no diagnóstico das neoplasias. Nanopartículas poliméricas utilizadas na liberação controlada de fármacos incrementam os procedimentos de terapia fotodinâmica (PDT), propiciando melhores resultados do que os obtidos com o uso de drogas convencionais. Texto truncado.

5

Validação de um espectro de 6MV e 15MV para um acelerador linear Varian Clinac 2300 C/D para a utilização em planejamentos radioterápicos com simulação de Monte Carlo

Campos LT', Da Rosa LAR', Cardoso SC ${ }^{2}$, Alves VGL ${ }^{2}$, Batista DVS ${ }^{3}$ Instituto de Radioproteção e Dosimetria, ${ }^{2}$ Instituto de Física da Universidade Federal do Rio de Janeiro, ${ }^{3}$ Instituto Nacional de Câncer - Rio de Janeiro - (RJ)

Introdução: Dentre os métodos disponíveis para o planejamento de tratamento em radioterapia, nenhum é mais acurado do que o método de Monte Carlo. Para sua implementação é necessário inserir um espectro semelhante àquele gerado pelo acelerador utilizado. Objetivos: Validar o espectro do Mohan et al. para um feixe de fótons gerado por potenciais de 6MV e 15MV. Métodos: O método de validação foi realizado comparando-se um PDP obtido por simulação de Monte Carlo com o EGSnrc, e um obtido com câmara de ionização para a água para o campo $10 \times 10 \mathrm{~cm}^{2}$ por um feixe de fótons de 6MV e $15 \mathrm{MV}$ gerado por um acelerador Varian Clinac $2300 \mathrm{C} / \mathrm{D}$. Foi utilizada a geometria de fatias cilíndricas, onde $R=L / \sqrt{\pi}$, sendo $\mathrm{L}$ o lado do campo quadrado e $\mathrm{R}$ o raio do cilindro. Resultados: $\mathrm{O}$ desvio máximo obtido entre as duas curvas de PDP, computacional e experimental, foi de $2 \%$ para $15 \mathrm{MV}$ e $1 \%$ para $6 \mathrm{MV}$ com incerteza das simulaçōes menor do que $1 \%$.

\section{O enfermeiro nas orientações ao paciente submetido à radioterapia}

\author{
Denardi UA, Martins AC, Moscatello ELM, Okane ESH, Bicudo F, Salvajoli JV \\ Hospital do Câncer AC Camargo - São Paulo - (SP)
}

O objetivo deste estudo é descrever os principais tópicos das orientações realizadas em um hospital de oncologia no setor de radioterapia com uma demanda de 250 atendimentos por mês; destes, a equipe de enfermagem realiza cerca de 200 orientações técnicas. Essas orientaçôes são divididas em gerais, antes ou após o planejamento, para exames: preparos, cuidados e orientações. Muitas dúvidas surgem desde o início ao término do tratamento, e cabe ao enfermeiro perceber as necessidades do cliente em tempo, hora e local adequado, assim como é de sua responsabilidade adaptar a linguagem e estratégia de ensino às orientaçôes fornecidas. Após o planejamento, todos os clientes são orientados sobre o tratamento em geral, o retorno médico e com a equipe de enfermagem para avaliar as condiçôes da pele. Nos tratamentos de braquiterapia, são realizadas as orientações quanto aos procedimentos a serem realizados. Todas as orientações são realizadas pessoalmente e, quando não é possível, por telefone ou via fax, visto a demanda de outras regiōes nacionais e até internacionais, sendo neste caso feita exclusivamente pelo enfermeiro do setor. Os autores discutem a grande quantidade de informaçóes e enfatizam a importância de o enfermeiro ser também educador no sentido de desenvolver habilidades para fornecer de forma clara, objetiva e didática os conteúdos; proporcionando, também, meios de os clientes participarem de forma ativa de tudo o que lhes é ensinado, visando a ajudá-los na superação dessa etapa, amenizando os efeitos colaterais e procurando o equilíbrio físico e emocional.

6

O uso de TLD LiF na dosimetria in vivo em radioterapia

Franco LO, de Almeida CE

Laboratório de Ciências Radiológicas (LCR/UERJ) - Rio de Janeiro - (RJ)

Objetivos: Implantar um sistema de dosimetria via postal, utilizando dosímetros termoluminescentes (TLDs) em pó, para avaliar as incertezas associadas e estimular o uso de medidas in vivo como parte de um programa de QA (quality assurance). Métodos: Posiciona-se o conjunto TLD + capa de build-up, no centro do campo de tratamento do paciente a ser irradiado. Após a irradiação, os TLD retornam ao Laboratório de Ciências Radiológicas, para avaliar a dose absorvida pelo TLD e comparar com o sistema de planejamento. Resultados: Quatro instituições participaram deste trabalho, e foram obtidos, em todas, os valores dentro do esperado, com pequenas variaçôes. Na primeira, foram irradiados 84 campos em 45 pacientes, sendo observado um desvio sistemático de aproximadamente $3 \%$, onde a posteriori foi comprovado como uma variação do fator de calibração, segundo acompanhamento feito com a câmara de ionização. Na segunda, foram irradiados 47 pacientes, dos quais $73 \%$ estavam de acordo e o restante comprovou uma possível variação do fator de calibração. Na terceira, foram irradiados 12 pacientes, obtendo-se uma resposta $100 \%$ positiva das leituras dos TLD. Na quarta, 63\% dos 29 pacientes estavam de acordo e o restante aponta para um possível erro de posicionamento dos TLD ou um equívoco nos cálculos do TPS. Conclusōes: Este estudo comprova a eficiência do método utilizado e vem propor métodos alternativos mais acessíveis do que os comercialmente disponíveis. 
Avaliação do planejamento tridimensional (3D) de pacientes com prótese femoral no tratamento de câncer de próstata

Verdiani AB, Rossi BT, Suguikawa E, Hara SH, Santos RS Hospital do Câncer AC Camargo - São Paulo - (SP)

Introdução: A dificuldade para planejar esse tipo de paciente está na presença da prótese nos campos de irradiação, cuja conseqüência é a perturbação na distribuição de dose, não podendo, assim, utilizar os campos usuais, como a técnica em "Box". A presença de inomogeneidades e o alto número atômico do material que compóe a prótese levam a um aumento da dose na interface tecido-prótese, devido principalmente ao retroespalhamento e à produção dos raios-x. Para feixes de fótons de alta voltagem esta variação de dose é acentuada, podendo acarretar graves consequiências para o paciente. Desta maneira, é importante que se evitem campos que incidam diretamente na região da prótese. Objetivos: Estabelecer o melhor método de planejamento 3D para pacientes de câncer de próstata com prótese de fêmur, comparando a dose nos órgãos de risco. Métodos: Foram estudados diversos pacientes com câncer de próstata, com diferentes volumes e estadiamentos clínicos, através do sistema de planejamento tridimensional Eclipse. Com a análise dos histogramas dose-volume (DVH) para os diferentes tipos de planejamento, foi possível quantificar a dose no reto, na bexiga, na próstata e na cabeça do fêmur. Resultados: Avaliando diferentes planejamentos, a técnica 4FBOX foi confirmada como sendo o método mais apropriado para a radioterapia convencional em câncer de próstata. Porém, a prótese femoral limita o uso desta técnica, cujos dados de DVH identificam duas alternativas, utilizando técnicas de três campos coplanares para esse tipo de tratamento. Texto truncado.

\section{Carcinoma de pequenas células de colo de} útero: relato de caso

Faroni L, Mendonça L, Viégas CMP, Araújo CMM Seção de Radioterapia do Instituto Nacional de Câncer - Rio de Janeiro - (RJ)

Introdução: $O$ câncer de colo uterino é a segunda neoplasia mais freqüente entre as mulheres no Brasil. O tipo histológico mais freqüente é o carcinoma escamoso (80\%), seguido pelo adenocarcinoma (10-15\%). Relato de caso: Relata-se um caso de câncer de colo uterino tipo "oat cell", devido à sua raridade: Paciente feminina, 66 anos, fez preventivo em novembro/ 2005 com biopsia, cujo laudo foi carcinoma de pequenas células tipo neuroendócrino ("oat cell"). Foi matriculada no INCA em janeiro/2006, após revisão de lâminas que confirmaram o diagnóstico prévio. No exame de admissão, a paciente apresentava lesão vegetante e infiltrante de todo o colo uterino, com invasão do terço superior da parede lateral direita da vagina, com possível infiltração do terço superior da parede posterior. Paramétrio esquerdo "estirado" até terço médio. PS. zero; USG abdominopélvico e cistoscopia normais. Na TC de pelve de fevereiro/ 2006 evidenciam-se duas imagens sólidas, ovaladas, localizadas nas regióes parauterina direita $(2,6 \mathrm{~cm})$ e esquerda $(2 \mathrm{~cm})$ que podem corresponder a linfonodomegalias ilíacas externas. A RNM desta mesma data confirma estes achados. Foi então submetida a tratamento quimioterápico entre fevereiro e junho de 2006 (6 ciclos de CDDP+ VP16 + Zofran + DxT), obtendo resposta completa da lesão. Realizou tratamento radioterápico adjuvante à QT na dose de 5000cGy em 25 fraçôes sobre pelve, seguido de braquiterapia de alta taxa, na dose de $24 \mathrm{~Gy}$ em 3 fraçōes de $8 \mathrm{~Gy}$ no ponto A, entre 02/08/2006 e 29/09/2006.
Proposta de consenso de sistematização de condutas no tratamento do câncer de próstata com radioterapia conformacional em 3 dimensões

Seixas C, Viégas CM, Bezerra ML, Mendonça LM, Araújo CM Instituto Nacional de Câncer - Rio de Janeiro - (RJ)

Introdução: $\mathrm{O}$ câncer de próstata é a neoplasia maligna mais comum em homens, excetuando os tumores cutâneos não-melanocíticos. Antes do advento do planejamento da radioterapia conformacional em 3 dimensões (RTC3D), o planejamento era realizado em duas dimensões, com campos de tratamento baseados em parâmetros anatômicos através de exames clínicos e filmes de radiografia convencional. A RTC3D é uma técnica desenvolvida para administrar, localizadamente, a radiação no tumor e excluir os tecidos normais adjacentes. Objetivos: Propor uma padronização de condutas em pacientes com câncer de próstata que são tratados com RTC3D no Instituto Nacional de Câncer e prestadores de serviço de Sistema Único de Saúde. Métodos: Análise da literatura disponível, incluindo os consensos publicados sobre o assunto. Resultados: Após análise da literatura foi realizada uma sistematização de condutas para padronizar os procedimentos realizados durante todas as etapas do processo necessário para o tratamento, incluindo os exames essenciais para indicá-lo, posicionamento recomendado, protocolos para a aquisição das imagens de tomografia computadorizada de pelve, normatização da marcação dos órgãos nas imagens, volume de tratamento de acordo com a estratificação de risco do paciente, dose prescrita, doses toleradas pelos tecidos normais, avaliação da qualidade do tratamento, avaliação do paciente durante o tratamento e conduta ao término do mesmo.

10

\section{Abordagem preventiva integrada de enfermagem e odontologia dos pacientes em radioterapia de cabeça e pescoço no Hospital do Servidor Público Estadual de São Paulo (HSPE)}

Araújo E, Lima MB, Ribeiro APV, Alves MJ

Hospital do Servidor Público Estadual de São Paulo (HSPE) - São Paulo - (SP)

Introdução: A abordagem multidisciplinar dos pacientes em radioterapia de cabeça e pescoço é importante para a prevenção e redução de eventuais efeitos adversos decorrentes do tratamento oncológico. Objetivos: Demonstrar a experiência recente de integração dos departamentos de enfermagem e de odontologia dentro do Serviço de Radioterapia do HSPE, na abordagem semanal de pacientes em radioterapia, com destaque para o uso do laser pelo profissional da odontologia. Métodos: Trabalho retrospectivo com 23 pacientes portadores de câncer de cabeça e pescoço, submetidos à radioterapia exclusiva $(43 \%)$ ou radioterapia com quimioterapia neo-adjuvante e/ou concomitante (57\%). Os pacientes foram submetidos à avaliaçáo odontológica e do serviço de enfermagem em consulta anterior ao início do tratamento e semanalmente durante a radioterapia. A abordagem da equipe de enfermagem visava, fundamentalmente, segundo protocolo próprio e orientação médica, a açôes de orientação e prevenção de eventuais sintomas decorrentes da radioterapia, em especial a mucosite. A abordagem odontológica visava a uma avaliação prévia, à radioterapia, da saúde bucal do paciente, com especial atenção para a eventual necessidade de procedimentos préradioterapia, doença periodontal, abscessos dentais ativos e higiene oral do indivíduo. Durante a radioterapia, 9 pacientes $(39,1 \%)$ receberam tratamento com laser, objetivando principalmente a diminuição dos sintomas da mucosite, a promoçăo da analgesia, o efeito antiinflamatório e de reparação tecidual.

Texto truncado

12 


\section{O câncer e a sexualidade da mulher}

\author{
Carvalho SMF, Albuquerque GA, Maia ER, Carvalho IOC
} Centro de Oncologia do Cariri - Barbalha - (CE)

Introdução: $\mathrm{O}$ surgimento de enfermidades mexe com a sexualidade feminina, principalmente o câncer, patologia associada à morte e alteração de auto-imagem. 0bjetivo: Analisar os impactos do câncer sobre a sexualidade da mulher. Métodos: Como parte de um projeto de extensão da Universidade Federal do Ceará que visa a apoiar mulheres com câncer, realizou-se um estudo-piloto de caráter descritivo. A coleta de dados foi realizada por meio de entrevistas semi-estruturadas no Centro de Oncologia do Cariri. Resultados: Foram entrevistadas 12 mulheres: 7 (83,3\%) tinham entre 40 e 60 anos; 8 (66,6\%) eram casadas; 9 (75\%) com diagnóstico de neoplasia de mama; $1(8,3 \%)$ de ovário; $1(8,3 \%)$ de colo uterino e 1 $(8,3 \%)$ de pulmão. Todas as pacientes com câncer mamário referiram angústia com a cirurgia: $9(75 \%)$ relataram alteração de humor; $5(41,7 \%)$ relataram irritabilidade; 4 (33,3\%), comportamento depressivo. Três pacientes $(25 \%)$ sentiam incômodo com a alopecia e $2(16,7 \%)$ com a radiodermite. Seis pacientes (50\%) relataram transtornos sexuais: $4(33,3 \%)$ tinham receio na prática sexual e $2(16,7 \%)$ referiram sentir vergonha do próprio corpo. Todas as casadas relataram medo de perder ou serem rejeitadas pelo parceiro. Conclusōes: As mulheres estudadas apresentaramse com a sexualidade fragilizada, conviviam com o temor da rejeição do parceiro sexual e com mitos potencializadores do não exercício de uma sexualidade saudável e prazerosa. Tornam-se vigentes estudos mais aprofundados, visando a delinear melhor o impacto gerado pelo câncer na sexualidade feminina, para que se promova acompanhamento mais eficaz e se diminuam conflitos e transtornos em tais pacientes.

13

Tratamento adjuvante do câncer gástrico com radioquimioterapia: experiência da Liga Norte Rio-Grandense Contra o Câncer/LNRCC

Gouveia NMD, Xavier RN, Santos ME, Barros D, Matias D, Souza CS Departamento de Radioterapia, Departamento de Oncologia Clínica/LNRCC - Natal -(RN)

Introdução: $\mathrm{O}$ esquema de adjuvância com radioquimioterapia para câncer gástrico, proposto pelo Intergroup trial-0116, mostrou ser um tratamento com potencial curativo quando instituído após abordagem cirúrgica adequada nos estadiamentos T3, T4 e/ou linfonodo positivo e/ ou margem cirúrgica exígua, apresentando benefício na sobrevida livre de doença e sobrevida global, em detrimento da toxicidade aguda e tardia do esquema referido. Objetivo: Analisar os pacientes portadores de neoplasia gástrica tratados na LNRCC, segundo o protocolo do Trial intergroup0116, no período de setembro de 2003 a maio de 2005. Métodos: Tratase de um estudo retrospectivo, avaliando 26 pacientes atendidos na LNRCC no período de setembro de 2003 a maio de 2005 , submetidos à gastrectomia total ou parcial com anatomopatológico evidenciando adenocarcinoma gástrico, estadiamentos T3-T4qN ou qTN positivo. Todos os pacientes foram tratados com radioterapia conformacional 3D, recebendo $45 \mathrm{~Gy}$ em 25 fraçōes. Quimioterapia foi realizada com 5-fluorouracil (5FU) $425 \mathrm{mg} / \mathrm{m}^{2} \mathrm{em}$ infusão contínua D1 mais leucovorin $20 \mathrm{mg} / \mathrm{m}^{2}$ de D1 a D5, sendo que 20 pacientes fizeram o mínimo de cinco ciclos de QT e destes apenas 3 fizeram xeloda ou UFT para completar o esquema terapêutico pela falta de 5FU. Resultados: Dos 26 pacientes analisados, a idade mediana encontrada foi 58 anos. O seguimento variou de 4 meses a 24 meses e neste período foi encontrados toxicidade hematológica GII em $41 \%$ e gastrintestinal GI em $32 \%$

Texto truncado.

15

\section{Câncer de mama: impactos da mastectomia}

Carvalho SMF, Silva CF, Maia ER, Carvalho IOC Centro de Oncologia do Cariri - Barbalha - (CE)

Introdução: A mastectomia faz muitas mulheres depararem-se com diferentes conflitos, como: insegurança quanto ao prognóstico, labilidade emocional, alteração de auto-imagem. Causa, portanto, impacto em diversas áreas e diminui a qualidade de vida. Objetivo: Avaliar os impactos da mastectomia em mulheres com câncer de mama. Métodos: Realizouse um estudo de caráter descritivo. A coleta de dados foi realizada por meio de entrevistas semi-estruturadas com mulheres mastectomizadas, no Centro de Oncologia do Cariri. Resultados: Foram entrevistadas 21 pacientes: $16(76,1 \%)$ tinham mais de 50 anos; 9 (42,9\%) eram casadas e $5(23,8 \%)$ eram viúvas. As alterações pós-mastectomias foram: 18 $(85,7 \%)$ eram católicas e referiram maior apego à religião; $12(57,1 \%)$ apresentaram alteração de sono-vigília; $5(23,8 \%)$ relataram piora na vida sexual (todas elas tinham menos de 40 anos), as mais idosas e viúvas não o fizeram; $6(28,5 \%)$ mencionaram maior proximidade com os parentes; $21(100 \%)$ evoluíram com labilidade emocional: apenas $2(9,5 \%)$ delas tiveram acompanhamento psicológico e $1(4,8 \%)$ usou medicação antidepressiva; $15(71,4 \%)$ referiram dor em membro superior homolateral à cirurgia; $18(85,7 \%)$ relataram edema e limitação de abdução do braço, dias após a mastectomia; somente $3(14,3 \%)$ persistiram com linfedema importante. Apenas $9(42,9 \%)$ tiveram acesso a tratamento fisioterápico. Conclusôes: A mastectomia é um processo mutilante e apresenta impactos em várias áreas da vida. É necessário que se promova uma terapêutica integral (multi e interdisciplinar) a mulheres submetidas a tal cirurgia, a fim de se minimizarem os transtornos decorrentes desse processo. 14

Análise da dose na pele para o feixe de fótons de 6MV para diferentes posicionamentos clínicos

Pedrini M, Sant'anna MC, Marcelino FAS, Santana JCA, Lima CSM Fundação Pio XII

Fótons de alta energia permitem a preservação da pele; no entanto, a magnitude desse efeito depende de parâmetros de posicionamento. Essa diferença é devido à contaminação de elétrons. Portanto, existe dose com a qual devemos nos preocupar. Com medidas organizadas quantificaremos valores para prevenir altas doses na pele. A dose de entrada para $6 \mathrm{MV}$ de 3 aceleradores foi medida sob várias condições. Usou-se câmara de ionização plana paralela, eletrômetro e simulador de água. Foram feitas medidas com a câmara na superfície e na profundidade de máxima dose $(1,5 \mathrm{~cm})$, escolhida para a normalização. Avaliou-se o aumento da dose na pele com o tamanho de campo. Isto era esperado por causa do aumento de espalhamento. Outro parâmetro é a diferença de distância do paciente à fonte. Conforme a distância, a fonte superfície aumenta e a dose na pele diminui. Muitas vezes, além do efeito da distância reduzida, utilizamse bandejas para a colimação. A bandeja aumenta a dose na pele, consideravelmente e, como não é grossa e tem baixo número atômico, a maioria dos elétrons gerados no cabeçote pode penetrá-la e alcançar o paciente. A dose para campo com filtro é menor do que para campo aberto, sugerindo que o filtro elimina mais elétrons gerados antes dele do que produz. Assim, conclui-se que para campos grandes, presença de blocos ou pequenas distâncias de tratamento deve-se prestar atenção especial. 


\section{Medidas do fator rendimento para campos de elétrons colimados em tratamentos individualizados}

Pedrini M, Sant'anna MC, Marcelino FAS, Santana JCA, Lima CSM Fundação Pio XII

Introdução: A maioria dos campos de elétrons usados no tratamento é definida pelos aplicadores. No entanto, muitas vezes são necessárias proteçōes adicionais. Prever a dose num campo de elétrons colimado não é imediato como para fótons. $\mathrm{O}$ ideal é fazer medidas para cada bloco. Objetivo: Caracterizar empiricamente o rendimento dos campos irregulares usados clinicamente, generalizando procedimentos. Métodos: Foram usados câmara de ionização, eletrômetro, simulador de água, posicionador automático e blocos. Mediu-se a produção de cargas na profundidade de referência (TRS 398) para 4, 6, 9, 12 e $15 \mathrm{MeV}$, com blocos e com o campo aberto. Resultados: Para os dados encontrados para blocos do aplicador $15 \mathrm{~cm}^{2}$ apenas um, com aproximadamente $95 \%$ da área colimada, apresentou uma queda no rendimento de até $8 \%$. No aplicador $10 \mathrm{~cm}^{2}$, uma colimação de $30 \%$ já apresenta uma diferença de $2 \%$. Um bloco encobriu parcialmente o eixo do feixe, onde estava a câmara, diminuindo a saída. No entanto, quando se mediu no ponto central da área colimada, a diferença desapareceu. Considerando a planura do feixe, deve-se descentralizar a câmara a fim de medir a saída real. Assim, cada serviço deve fazer medidas para se certificarem dos limites em que não há necessidade de correção. Conclusões: Conclui-se que, em nosso Serviço, deve-se medir sempre que ocorrer: energias de $4 \mathrm{MeV}$ e $6 \mathrm{MeV}$, aplicadores $\mathrm{cm}^{2}$ e $10 \mathrm{~cm}^{2}$ e colimação maior do que $80 \%$.

\section{7}

\section{Braquiterapia de baixa taxa de dose no câncer de próstata}

Franca CAS, Vieira SL, Penna ABRC

Radioterapia Botafogo - Instituto Brasileiro de Oncologia (IBO) - Rio de Janeiro - (RJ)

Introdução: A incidência de câncer de próstata no Brasil é de 51 casos a cada 100.000 homens. Os pacientes com câncer de próstata foram classificados de acordo com o Risco de Seattle em: Baixo - PSA $\leq 10,0 \mathrm{ng} /$ $\mathrm{ml}$, Gleason $<7$ e estágio $<\mathrm{T} 2 \mathrm{c}$ (TNM); Intermediário - PSA $>10,0 \mathrm{ng} / \mathrm{ml}$ ou Gleason $\geq 7$ ou estágio $=\mathrm{T} 2 \mathrm{c}\left(\mathrm{TNM}^{3}\right)$ (somente um fator de risco); Alto - dois ou mais fatores de risco. Objetivo: Reportar a experiência do grupo no tratamento do câncer de próstata pela braquiterapia com sementes de Iodo-125 (B-I ${ }^{125}$ ), pelos valores do PSA. Métodos: Foram avaliados 88 pacientes, com idade média 67,6 anos (46-90 anos) entre os anos de 1998 e 2004: 46 pacientes $(52,3 \%)$ receberam hormonioterapia neo-adjuvante e $16(18,2 \%)$ receberam radioterapia externa associada. O PSA inicial médio foi de 13,7ng/ml (3,2-70ng/ml). A média do Gleason foi de 6 (29). O seguimento médio foi de 67,6 meses (13-103 meses). A definição de recidiva bioquímica utilizada foi o consenso ASTRO. Resultados: Dos pacientes, 28 (31,8\%) eram de baixo risco; 36 (40,9\%) de risco intermediário e $24(27,3 \%)$ de alto risco. Baixo risco: 25 pacientes $(89,3 \%)$ com doença sob controle bioquímico (CB) e $3(10,7 \%)$ com recidiva bioquímica $(\mathrm{RB})$. Risco intermediário: 23 pacientes $(63,9 \%)$ com doença sob CB e $13(36,1 \%)$ com RB. Alto risco: 13 pacientes $(54,2 \%)$ com doença sob CB e $11(45,8 \%)$ com RB. Avaliação global: 61 pacientes $(69,3 \%)$ com doença sob CB e 27 (30,7\%) com RB. Conclusão: A B-I ${ }^{125}$ apresenta preferência crescente na terapêutica do câncer de próstata localizado, devido aos resultados de $\mathrm{CB}$ da doença.

19
Dosimetria pós-implante de próstata com Iodo125: experiência do Hospital Sírio-Libanês (SP)

\section{Hanna SA, Capella EC, Gadia R, Neto AIC, Haddad CMK, Silva JLF} Hospital Sírio-Libanês (HSL) - São Paulo - (SP)

Introdução: Dosimetria pós-implante (DPI) é fundamental para o controle de qualidade em braquiterapia. Normas da American Brachytherapy Society (ABS) e publicaçōes pertinentes mostram que alguns parâmetros melhoram resultados e minimizam toxicidade. Objetivos: Descrever a metodologia padronizada pela instituição para DPI, analisar dados coletados e compará-los com a literatura. Métodos: Foram realizados 554 implantes (junho/2006) no HSL, com DPI no mesmo dia na maioria, sendo analisados 350 pacientes com dados completos. Todos realizaram braquiterapia com Iodo125 guiada por ultra-som e fluoroscópio, seguida por tomografia em posição padronizada com envio das imagens ao sistema de planejamento. As estruturas na tomografia foram reconhecidas e delimitadas utilizando-se sobreposição dos volumes pré-implante. Foram obtidos V100, V90, V150, D90, Dmáx e Dmín uretral. Resultados: A média e mediana foram obtidas: V100 (94,09\% e $91,03 \%)$, V90 (98,89\% e $94,49 \%)$, V150 (42,72\% e $22,67 \%)$, D90 (13672cGy e 13276cGy), Dmáx (15262cGy e 15307cGy), Dmín (8201cGy e 8286cGy), número de agulhas (25 e 26) e de sementes (88 e 88). Segundo recomendações da ABS, estes parâmetros devem ser reportados e cada instituição deve estabelecer sua rotina de DPI. O D90 e V150 respeitam recomendaçōes da $\mathrm{ABS}$ e da literatura na maioria dos pacientes. Conclusões: A DPI é realizada segundo recomendaçóes da ABS no HSL e esses dados merecem ser correlacionados com o seguimento clínico dos pacientes.

\section{Avaliação das doses de nêutrons em aceleradores lineares clínicos}

Rivera JC', Falcao R' ${ }^{2}$ de Almeida CE 'Laboratório de Ciências Radiológicas, LCR/UERG - Rio de Janeiro (RJ), ${ }^{2}$ Comissão Nacional de Energia Nuclear (CNEN) - Rio de Janeiro - (RJ)

A utilizaçăo de feixes de fótons ou elétrons de alta energia em tratamentos radioterápicos produz uma contribuição adicional à dose no paciente e nos trabalhadores ocupacionalmente expostos, devido aos nêutrons. As avaliaçōes das doses por nêutrons podem ser realizadas através de simulaçōes de Monte Carlo e/ou mediçóes experimentais. Foram utilizados detectores de bolhas BTI-PND para medir as doses de nêutrons no isocentro, a $1,41 \mathrm{~m}$ do alvo e nas distâncias ao longo da mesa de tratamento, com campo de $10 \mathrm{~cm}^{2} \times 10 \mathrm{~cm}^{2}$. Para este experimento foram utilizados quatro aceleradores lineares com diferentes energias nominais de fótons, localizados em hospitais da cidade do Rio de Janeiro e de São Paulo. Os resultados da dose nas distâncias ao longo da mesa foram comparados com valores publicados por Nisy Ipe. O presente trabalho indica que o detector de bolhas é uma ferramenta adequada para realizar mediçóes de dose de nêutrons produzidos por aceleradores lineares de uso clínico, sendo que os resultados da dose para a distância de $1,41 \mathrm{~m}$ do alvo aproximam-se dos valores publicados por McGynley. 


\section{Estudo da dose no músculo cardíaco devido à radioterapia do câncer de mama}

Varela $\mathrm{A}^{\prime}$, Canary $\mathrm{PC}^{2}$, de Almeida $\mathrm{CE}^{\mathrm{I}}$ 'Laboratório de Ciências Radiológicas (LCR/UERJ) - Rio de Janeiro - (RJ), ${ }^{2}$ Hospital Universitário Clementino Fraga Filho (UFRJ) - Rio de Janeiro - (RJ)

Introdução: No tratamento da mama esquerda, pela geometria espacial dos campos de radiação e da posição anatômica do coração, da coronária e do ventrículo esquerdo, estes podem estar sendo irradiados com doses que poderiam aumentar a probabilidade do desenvolvimento de cardiopatias, comprometendo a saúde do paciente a longo prazo. Tornase de suma importância procurar determinar os níveis de dose recebidos e analisar possíveis metodologias para minimizar a dose no volume cardíaco. Métodos: Obter imagens do simulador Alderson num CT-SIM da GE, e utilizá-las para o planejamento da irradiação do fantoma com a técnica convencional de campos tangenciais e opostos, utilizando o Sistema de Planejamento Cad Plan. Para determinar a dose absorvida nos pontos de interesse, foram utilizados TLD em pó, colocados nos pontos de interesse do fantoma. Para completar as informaçóes do TLD, foram colocados filmes radiográficos Kodak X-Omat V entre as fatias do fantoma no mesmo plano das cápsulas. Resultados Preliminares: Foi definida a posição espacial do volume cardíaco no fantoma, assim como a posição e volume da mama interna a ser simulada. Cápsulas de polietileno contendo TLD em pó foram colocadas nas posiçōes definidas na tomografia além de filmes para confirmar os valores definidos pelo sistema de planejamento. Os resultados preliminares indicam que a metodologia proposta é suficientemente sensível e adaptável à geometria espacial que envolve o tratamento de medida. Comparando os valores do sistema de planejamento e as leituras dos TLD, a diferença máxima encontrada foi de $30 \%$, uma vez que a heterogeneidade não foi considerada no cálculo. Texto truncado.

Fisioterapia durante a radioterapia em mulheres em tratamento por câncer de mama

Oliveira MMF, Souza MM, Okubo MA, Morais SS, Souza GA, Gurgel MSC Serviço de Fisioterapia - Centro de Atenção Integral à Saúde da Mulher - Universidade Estadual de Campinas - Campinas - (SP)

Objetivo: Verificar a influência da fisioterapia durante a radioterapia nas complicaçôes físicas loco-regionais. Métodos: Ensaio clínico controlado randomizado, com 68 mulheres em tratamento radioterápico por câncer de mama; alocadas 36 no Grupo 1 (G1), tendo realizado exercícios supervisionados 3 vezes por semana, e 32 pacientes no Grupo 2 (G2) grupo-controle. A ADM (flexão, abdução e rotação externa) do ombro foi avaliada pela goniometria; a circunferência do braço, pela cirtometria, e a aderência cicatricial, pela palpação cicatricial. A capacidade funcional foi graduada pelo escore de dificuldade para realizar atividades cotidianas. As avaliaçōes foram realizadas no início e ao final da RT. Para cálculos estatísticos, foi utilizado o teste de Mann-Whitney. Resultados: A idade média inicial foi de 50,7 anos. A distribuição por tipo de cirurgia, estadiamento, tratamentos complementares (quimioterapia e hormonioterapia) foi homogênea. O G1 apresentou maior ADM de flexão, abdução e rotação externa em relação ao $\mathrm{G} 2$, nos diferentes momentos da avaliação, $p=0,0001,0,0001$ e 0,0143 , respectivamente. $O$ aumento no volume do braço e aderência cicatricial foi menor no $\mathrm{G} 1$ em relação ao G2. Observou-se menor comprometimento da capacidade funcional no G1, principalmente para carregar compras. Ao se comparar as doses empregadas para plastrão - $4500(11 \%)$ e $5040(89 \%)$ - e sua associação à irradiação de fossa-supraclavicular (68\%), não foram observadas diferenças nas complicaçōes físicas entre os grupos. Conclusão: A fisioterapia previne complicaçóes desencadeadas pela irradiação, melhora as condiçóes de vida e acelera o retorno nas suas atividades de vida diária, familiar e social.

23

\section{Remodelamento cardíaco em ratos wistar irradiados: uma análise temporal}

Ferreira-Machado SC', Rocha NN3, Ribeiro $\mathrm{AF}^{2}$, Mac Dowel-Coimbra $\mathrm{AC}^{2}$, Peres $\mathrm{A}^{5}$, Oliveira JLP5 , Cabral-Neto J', Bouskelá $\mathrm{E}^{4}$, de Almeida $\mathrm{CE}^{2}$ 'Instituto de Biofísica Carlos Chagas Filho (UFRJ), '2Laboratório de Ciências Radiológicas (LCR/UERJ), ${ }^{3}$ Departamento de Fisiologia e Farmacologia (UFF), ${ }^{4}$ Laboratório de Pesquisas em Microcirculação (UERJ), UUFRJ/ Serviço de Radioterapia HUCFF - Rio de Janeiro - (RJ)

Introdução: Novos casos de câncer de mama surgem a cada ano no Brasil, e parte desta população é submetida à radioterapia. Considerando que o feixe de radiação também atinge os tecidos normais em volta do tumor, torna-se de suma importância avaliar as modificações fisiológicas em órgãos incluídos na área de tratamento. Objetivo: Caracterizar as possíveis alterações fisiológicas no coração de ratos Wistar, após 4 meses e 8 meses de irradiação, com uma dose única de $15 \mathrm{~Gy}$. Métodos: Neste projeto foi utilizado como modelo ratos Wistar (machos e fêmeas). Os mesmos foram irradiados no coração com dose única de $15 \mathrm{~Gy}$ com um feixe de fótons de 6MV. Após quatro meses e oito meses da irradiação, a avaliação funcional do coração foi realizada através de ecocardiograma comparando animais irradiados com controles. Resultados: No tempo de análise de 4 meses, os dados sugerem uma alteração na fração de ejeção e no débito cardíaco. Nota-se também um aumento no diâmetro do ventrículo, uma redução da espessura do septo e da parede posterior e um déficit diastólico. Enquanto que com 8 meses observa-se um quadro de hipertrofia com o aumento do débito cardíaco, um aumento da espessura do pericárdio e uma redução da relação aorta/átrio. A diferença significativa observada em relação a alguns parâmetros cardíacos, entre os ratos irradiados e os ratoscontrole, corrobora as manifestaçōes clínicas observadas em pacientes submetidas ao tratamento radioterápico. Conclusão: A expectativa deste estudo é que os resultados terão repercussão no planejamento prognóstico para tratamento de câncer de mama.

22

\section{Balão retal para radioterapia de próstata -} benefício ou detrimento?

de Paula LP1,2, Kaurin $\mathrm{D}^{2}, \mathrm{He} \mathrm{T}^{2}$, Hung AY ${ }^{2}$ 'CEBROM - Goiânia - (GO), ${ }^{2}$ OHSU - Portland - (OR, USA)

Introdução: $\mathrm{Na}$ radioterapia do câncer de próstata $(\mathrm{CaP})$, o balão retal (BR) serve para imobilizar a próstata e reduzir o volume retal da região de altas doses. Previamente, observou-se compressão da Fascia Retovesical (FRV) e aproximação da parede retal (PR) do volume alvo pelo BR. Objetivos: Analisar o efeito do BR tipo EZ na dosimetria do reto. Métodos: 10 pacientes com $\mathrm{CaP}$ tratados com IMRT fizeram tomografias (TC) com e sem o BR $(60 \mathrm{ml}$ de ar). Órgãos de interesse foram delineados, mantendo $3 \%$ de equivalência entre as TC. O volume da PR foi determinado baseado nas espessuras de $5 \mathrm{~mm}$ sem o BR ou $2,5-3 \mathrm{~mm}$ na presença dele. Distâncias entre próstata, vesículas e PR foram usadas como representativas da espessura da FRV e correlacionadas com doses na PR. Resultados: A espessura média da FRV foi $6 \mathrm{~mm}$ no ápice, $24 \mathrm{~mm}$ na base e $9 \mathrm{~mm}$ na região média prostática sem o BR e $5 \mathrm{~mm}, 12 \mathrm{~mm}$ e $4 \mathrm{~mm}$ com balão. Em 50Gy, o BR beneficiou 5 pacientes, reduzindo de $1-14 \%$ o volume de PR exposto. $\mathrm{Na}$ isodose de 60Gy, em 7 pacientes, houve aumento de até $26 \%$. Acima de 60Gy todos tiveram mais PR irradiada devido ao balão. Conclusão: $\mathrm{O}$ BR tipo EZ beneficiou a poucos pacientes. Ocorreu maior exposição de PR sempre que isodoses mais altas foram avaliadas. Este estudo confirma a aproximação da PR das regiōes de alta dose devido à compressão da FRV. 


\section{Situação das instalações com PET no Brasil}

\author{
Santos JA', Nogueira TM', Facure A', Sá LV², Gutterres RF ${ }^{1}$ \\ 'Coordenação Geral de Instalações Médicas e Industriais (CGMI)/Comissão Nacional de \\ Energia Nuclear (CNEN) - Rio de Janeiro - (RJ), \\ ${ }^{2}$ Serviço de Física Médica/Instituto de Radioproterção e Dosimetria (IRD)/Comissão \\ Nacional de Energia Nuclear (CNEN) - Rio de Janeiro - (RJ)
}

Objetivo: Analisar a situação dos tomógrafos PET (positron emission tomography) no Brasil, do ponto de vista do licenciamento. Os SMN (Serviços de Medicina Nuclear) utilizam em sua rotina calibradores de radionuclídeos para medir a atividade de soluçóes contendo radiofármacos como ${ }^{131} \mathrm{I},{ }^{67} \mathrm{Ga}$ e ${ }^{99 \mathrm{~m}} \mathrm{Tc}$, entre outros. Estas soluçōes são administradas a pacientes com o propósito de obter o diagnóstico de doenças ou sua terapia; o procedimento é simples: a dose de radiofármaco a ser administrada ao paciente é medida no calibrador de radionuclídeo e, após a administração e absorção do medicamento, o paciente realiza uma tomografia computadorizada (CT). O PET é um tomógrafo de geração mais avançada que o CT e detecta dois fótons num sistema de coincidência; para tal, utiliza o ${ }^{18} \mathrm{~F}$, um radiofármaco que emite dois raios gama de $511 \mathrm{keV}$. A realização de exames com ${ }^{18} \mathrm{~F}$ é semelhante a outros exames de medicina nuclear, mas o projeto de uma instalação com PET requer uma série de requisitos que não se aplicam num SMN convencional, ou seja, sem PET. Entre esses aspectos, pode-se destacar o tratamento do paciente injetado com ${ }^{18} \mathrm{~F}$, a dosimetria dos indivíduos ocupacionalmente expostos da instalação e a blindagem da instalação. Existe uma grande lacuna na literatura brasileira sobre este assunto e, inclusive nas Normas da Comissão Nacional de Energia Nuclear (CNEN) - órgão que licencia instalações nucleares e radioativas no Brasil, não existem itens específicos contemplando instalaçôes com PET. Este trabalho pretende minimizar esta lacuna e evidencia a necessidade de estudos direcionados à realidade brasileira no tocante ao PET.

25

\section{Rede brasileira de calibração de ativímetros}

\author{
Santos JA, Nogueira TM \\ Coordenação Geral de Instalações Médicas e Industriais (CGMI) / Comissão Nacional \\ de Energia Nuclear (CNEN) - Rio de Janeiro - (RJ)
}

Os ativímetros são instrumentos utilizados nos Serviços de Medicina Nuclear (SMN) para a determinação da atividade dos radiofármacos a serem administrados aos pacientes para propósitos de diagnóstico ou terapia. Muitos esforços vêm sendo feitos para melhorar a qualidade das mediçôes de radiofármacos. Desde 1998, por exemplo, o Laboratório Nacional de Metrologia das Radiaçóes Ionizantes (LNMRI), do Instituto de Radioproteção e Dosimetria da Comissão Nacional de Energia Nuclear (IRD/CNEN), com delegaçáo do Instituto Nacional de Metrologia e Qualidade Industrial (INMETRO), vem conduzindo um programa de intercomparação para mediçōes de atividades de radiofármacos, através do qual foi possível identificar falhas em equipamentos e procedimentos técnicos utilizados pelos $\mathrm{SMN}$ do país. A Norma CNEN-NN-3.05, em vigor, transfere toda a responsabilidade da segurança do desempenho dos ativímetros para os SMN ao determinar que estes realizem os testes de exatidão, precisão, reprodutibilidade e linearidade dos ativímetros e registrem os resultados obtidos. O objetivo deste trabalho é propor a implementação da Rede Brasileira de Calibração de Ativímetros (RBCA) formada inicialmente pelo LNMRI, pelo Laboratório de Calibração de Instrumentos do Instituto de Pesquisas Energéticas (IPEN/CNEN), pelo DIPLAN (Distrito do Planalto Central/CNEN), e pelo ESPOA (Escritório de Porto Alegre/UFRGS/CNEN). Como conseqüência, propōe-se a alteração da Norma CNEN-NN-3.05 que passaria a exigir a calibração periódica (a ser definida) dos ativímetros por Laboratórios integrantes da RBCA, mantendo-se a exigência da realização e registro dos testes de rotina dos ativímetros por parte dos $\mathrm{SMN}$.

27

\section{Controle de qualidade de placas de SR-90 para uso dermatológico}

\author{
Watanabe $\mathrm{EY}^{1}$, Pereira $\mathrm{GC}^{2}$, Pereira A ${ }^{3}$ \\ 'Hospital do Câncer AC Camargo - São Paulo - (SP), \\ ${ }^{2}$ Centro Infantil Boldrini, Campinas - (SP), \\ ${ }^{3}$ Centro Paulista de Radioterapia e Oncologia - CEPRO/CLINRAD - São Paulo - (SP)
}

Introdução: A utilização de placas de $\mathrm{Sr}-90$ para tratamentos dermatológicos é freqüiente na radioterapia, contudo, a maioria dessas placas é antiga e não sofre qualquer tipo de controle de qualidade (CQ). O CQ se faz necessário para assegurar a integridade das placas em relação à dose de radiação, ao perfil de dose e ao tamanho da área ativa de cada placa. Objetivo: Realizar um CQ das placas dermatológicas de Sr-90. Métodos: Foram sensibilizados filmes, através do contato direto com as placas para tempos de exposição determinados. Depois de revelados, analisaram-se os filmes, utilizando-se um scanner e um software apropriados. A partir das densidades óticas medidas e das doses calculadas para cada tempo de exposição, fez-se uma curva de calibração e calcularam-se os valores de dose com o rendimento de cada placa, mediu-se também o tamanho de campo definido pela isodose de $50 \%$. Por fim, simulou-se o tratamento de uma cicatriz, na presença e na ausência de um gap de $0,2 \mathrm{~cm}$. Resultados: Em relação ao tamanho de campo, observaramse diferenças entre o valor nominal e o medido, menores que $8 \%$ tanto no eixo x quanto no y. Quanto à dose, obtiveram-se diferenças entre a dose calculada e a medida, menores do que $3 \%$. Finalmente, em relação ao gap, observou-se uma subdosagem nessa região. Texto truncado.

Velocidade de PSA não é fator preditivo significante na evolução do câncer de próstata em população heterogênea

\author{
dePaula LP1,4, Garzotto M², Mogogue-Tchokote $S^{3}$, Hung AY ${ }^{4}$ \\ 'Centro Brasileiro de Radioterapia Oncologia e Mastologia, Goiânia - (GO), ${ }^{2}$ Urologia \\ ${ }^{3}$ Bioestatística ${ }^{4}$ Radioterapia - Oregon Health and Science University, Portland -OR
}

Objetivos: Em população selecionada (PSA médio 4,3ng/ml), a velocidade de aumento de PSA (VPSA) mostrou ser fator prognóstico para a mortalidade específica por câncer de próstata $(\mathrm{CaP})$. Este estudo objetiva confirmar o valor da VPSA em população heterogênea; analisar também a relação da VPSA com sobrevida livre de doença (SLD), sobrevida e sobrevida específica por câncer de próstata (SECaP). Métodos: 643 pacientes com CaP, dos quais 375 receberam tratamento definitivo, sendo 195 prostatectomia radical e 180 radioterapia. 372 pacientes tinham pelo menos um PSA pré-tratamento e 305 tinham pelo menos dois valores para cálculo da VPSA. Recorrência bioquímica foi definida sendo PSA nadir + 2. Classificação de Gleason (GS), VPSA e estadiamento foram analisados. Resultados: Após follow-up médio de 53,3 meses, ocorreram 37 mortes e 53 recorrências bioquímicas. Sobrevida em 5 anos foi de $90,8 \%$ e SLD foi de $93,1 \%$. Apenas 5 pacientes morreram devido a CaP, resultando em SECaP de $98,6 \%$ em 5 anos. Em análise multivariada, GS foi o único fator significante para Sobrevida e SLD. Em análise uni/mulitvariada, VPSA não se mostrou significante. Conclusão: Em população heterogênea encaminhada aleatoriamente devido à PSA elevado, VPSA prétratamento não é fator significante preditivo da evolução do $\mathrm{CaP}$. O fator mais significante no impacto da sobrevida desses pacientes continua sendo GS. 


\section{Avaliação preliminar de pacientes com câncer de próstata submetidos à 3D-CRT}

\author{
Fortuna APD, Potamianos CF, Deus CC, Feitosa SM, Dias RS, Giordani AJ \\ Segreto HRC, Segreto RA \\ HSP/UNIFESP - São Paulo - (SP)
}

\section{Dosimetria para construção do filtro utilizado em radioterapia intra-operatória de mama}

\author{
Watanabe EY', Felipe DS', Boccaletti KW', Pereira $\mathrm{A}^{3}$ \\ 'Hospital do Câncer - AC Camargo - São Paulo - (SP), \\ ${ }^{2}$ Hospital Erasto Gaertner - Curitiba - (PR),
} ${ }^{3}$ Centro Paulista de Radioterapia e Oncologia (CEPRO/CLINRAD) - São Paulo - (SP)

Introdução: A radioterapia intra-operatória (IORT) tem como objetivo administrar altas doses de radiação em uma única fração, reduzindo a dose em tecidos normais adjacentes. Na IORT de mama, o leito tumoral está próximo à parede torácica e por isso existe a necessidade de se utilizar uma proteção para a mesma, que pode ser feita de diversos materiais e espessuras. Objetivo: Determinar a espessura e o tipo de filtro para o disco de proteção de modo que a transmissão (TR) e o retroespalhamento (RTE) na parede torácica e tecidos normais sejam reduzidos a valores aceitáveis, e que a colocação e a assepsia sejam de fácil realização. Métodos: Utilizouse um fantoma, filmes, filtros de chumbo, de alumínio, de acrílico e cone para IORT de $57 \mathrm{~mm}$ de diâmetro. As irradiaçōes foram feitas num acelerador linear com energias de $6 \mathrm{MeV}$ e $9 \mathrm{MeV}$ de elétrons. Realizou-se a dosimetria dos filtros, variando-se a espessura dos mesmos para avaliar a TR e o RTE. Resultados: Para a energia de $6 \mathrm{MeV}$, a melhor combinação de filtros obtida foi $3 \mathrm{mmPb}, 2,5 \mathrm{mmAl}$ e $2 \mathrm{~mm}$ de acrílico que resultava em uma TR de $7 \%$ e um RTE de $8 \%$; para $9 \mathrm{MeV}$ a combinaçáo mais adequada foi de $3 \mathrm{mmPb}, 3 \mathrm{mmAl}$ e $2 \mathrm{~mm}$ de acrílico, cuja TR e RTE foram de $8 \%$ e $9 \%$, respectivamente. Conclusōes: A presença do filtro de chumbo de $3 \mathrm{~mm}$ é suficiente para reduzir a TR na parede torácica a valores aceitáveis, porém aumenta a quantidade de RTE, por isso houve a necessidade de se colocar o filtro de alumínio. A presença do acrílico é justificada pela diminuição do RTE e pela maior facilidade de assepsia do conjunto. Recomenda-se que o filtro seja o menor possível para facilitar a colocação na paciente, porém é necessário que tenha um diâmetro no mínimo de $2 \mathrm{~cm}$ além do cone.

30

Efeitos adversos tardios da radioterapia na função sexual feminina

Vidal MLB, Almeida LM, Borba MMSC, Souza CQS Instituto Nacional de Câncer - Rio de Janeiro - (RJ)

Introdução: Apesar do aperfeiçoamento tecnológico da radioterapia, esta ainda causa efeitos adversos em um percentual elevado de mulheres. A valorização do evento pelos profissionais de saúde é imprescindível na intervençáo. Objetivo: Identificar efeitos adversos tardios na função sexual subseqüente ao tratamento radioterápico em mulheres com carcinoma de colo uterino nos estágios IA1 a IIIB, bem como o perfil sociodemográfico, o estadiamento e a radioterapia empregada. Métodos: Foi realizado estudo epidemiológico observacional descritivo do tipo transversal, desenvolvido no Hospital do Câncer II (INCA/MS). Foram incluídas pacientes com mínimo de 91 dias de pós-radioterapia, e excluídas as com outro câncer concomitante, recidiva, HIV positivo, sem prontuário ou CLE não assinado. Resultados: A idade, a escolaridade, o nível socioeconômico e o estadiamento no diagnóstico coincidiram com o perfil de câncer de colo uterino descrito na literatura científica. A área referida como mais afetada pelas pacientes foi nenhuma (34\%), seguida da intestinal $(30 \%)$, urinária $(20 \%)$ e sexual $(16 \%)$, porém houve um percentual elevado de respostas positivas a sinais e sintomas de disfunçáo sexual entre as sexualmente ativas (73\%). Conclusōes: O fato de a freqüência de disfunção sexual ter sido elevada e, na percepção das pacientes não ter sido referida como área que mais as afetava, mostra que relevam a funçáo sexual a segundo plano no pós-tratamento, em comparação com a função intestinal. Isso exige uma melhor busca desses efeitos nas consultas subsequentes ao tratamento, incluindo a disfunção sexual, já que não é referida como queixa pelas pacientes, embora as afete com grau de severidade importante, possibilitando intervenção interdisciplinar e minimização desse quadro. 31 
Uma sucinta determinação de desempenho de uma unidade de teleterapia de quilovoltagem "Stabilipam II Siemens"

Sant'Anna MC, Pedrini M, Marcelino FAS, Santana JCA, Lima CSM Fundação Pio XII

Introdução: As unidades de radioterapia de quilovoltagem embora ofuscadas, primeiro pelas unidades de cobalto e depois pelos aceleradores lineares, permanecem úteis dentro das energias disponíveis em radioterapia. Os feixes de baixa energia têm aplicaçōes no tratamento de lesōes da pele e tumores rasos. Um programa de qualidade precisa ter o mesmo rigor que unidades mais modernas de maneira a garantir segurança e precisão nas doses entregues. Objetivo: Avaliar o desempenho do equipamento, gerando resultados que serão apresentados como parâmetros usados na rotina. Métodos: Usamos placas de alumínio, câmara de ionização cilíndrica e placas paralelas, eletrômetro e simulador de $36 \mathrm{~cm}^{3}$ de água com posicionador automático remoto. Ao encontrar o valor da camada semi-redutora (CSR) e da quarto-redutora (CQR) observa-se a qualidade do feixe. Os valores estão próximos aos publicados pelo British Journal of Radiology. Resultados: Os dados de porcentagem de dose profunda gerados oferecem confiabilidade quando comparados com o BJR. Os valores de retroespalhamento levantados são usados no cálculo do rendimento dos aplicadores. Comparados com o BJR, apresentam um erro percentual de até $9 \%$. Conclusões: Unidades de quilovoltagem são de manutenção mais simples e barata em comparação com os modernos aceleradores lineares. Em um programa de garantia da qualidade para unidades recémadquiridas é necessário ao físico avaliar informaçôes básicas que serão referências para a vida útil do aparelho.

33

\section{Comparação entre planejamentos} convencional e conformacional utilizados em tratamento de tumores de cabeça e pescoço com invasão de cavidade nasal

Sales CP, Oliveira EFCMS, Rubo RA, Villar RC, Pássaro AM, Rodrigues LN Instituto de Radiologia do Hospital das Clínicas da Faculdade de Medicina da Universidade de São Paulo - São Paulo - (SP)

Introdução: Tumores de cabeça e pescoço que invadem cavidade nasal podem ser tratados com três campos faciais, dois campos cérvico-faciais paralelos-opostos e um campo direto de fossa supraclavicular. Em tratamentos $3 \mathrm{D}$ conformacionais, utiliza-se geralmente a mesma composição, porém, com blocos próprios que conformam o volume alvo de planejamento. Objetivo: Comparar a técnica convencional vs 3D conformacional nesse arranjo de 6 campos. Métodos: Foram analisados 6 pacientes planejados com técnica 3D conformacional no software Eclipse (Varian $\left.{ }^{\circledR}\right)$ e simulouse a técnica convencional com blocos manuais. Resultados: A análise do histograma dose-volume mostrou que no planejamento convencional, $95 \%$ do volume-alvo receberia dose variando entre $80 \%$ e $102 \%$ da prescrição, enquanto que no conformacional recebeu entre $94 \%$ e $103 \%$. As técnicas não diferiram quanto à dose máxima da medula espinhal. Para o quiasma, a dose máxima foi maior no planejamento convencional, com diferença mínima de $18 \%$, e para os olhos foi maior no planejamento conformacional, com diferença mínima de 6\%. Conclusão: Concluiu-se que mesmo para grandes volumes-alvo, neste tipo de caso, a técnica 3D conformacional apresenta vantagens, sendo possível melhorar a relação entre distribuição de dose no alvo e a dose recebida pelos órgãos de risco.

\section{Avaliação de margens no planejamento} tridimensional de câncer de pulmão

Silva CVC, Pássaro AM, Furnari L, Stuart SR, Carvalho HA Serviço de Radioterapia - InRad - HCFMUSP - São Paulo - (SP)

Objetivo: Verificar a adequação das margens de segurança pré-estabelecidas para a definição do PTV em pacientes com câncer de pulmão. Métodos: Foram estudados 10 pacientes com tumor de pulmão, 5 destes no lobo superior, 3 na regiāo central e 2 no lobo inferior. A tomografia computadorizada (TC) de planejamento foi realizada em 3 tempos: respiração normal, inspiraçāo e expiração máximas. Os contornos das estruturas de interesse foram delineados na TC em respiração normal. As margens estabelecidas para o PTV nesta instituição são $1,0 \mathrm{~cm}$ a $1,5 \mathrm{~cm}$ no plano transversal e $1,5 \mathrm{~cm}$ a $2,0 \mathrm{~cm}$ no plano crânio-caudal. Foram delineados, em seguida, os GTV de inspiração e o de expiração nas respectivas TC, que foram sobrepostos aos volumes desenhados na TC em respiração normal. A avaliação da movimentação dos GTV foi feita a partir da medida da distância entre os isocentros dos GTV da inspiração, da expiração e o normal, nos 3 eixos de coordenadas: $x$ (látero-lateral), y (ântero-posterior) e $\mathrm{z}$ (crânio-caudal). Resultados: $\mathrm{O}$ maior deslocamento ocorreu nos tumores de terço inferior no sentido crânio-caudal na inspiração $(1,8 \mathrm{~cm})$, e no sentido ântero-posterior na expiração $(1,2 \mathrm{~cm})$. O percentual de volume dos GTV (inspiração e expiração) encontrado fora do PTV variou de $0 \%$ (tumores centrais, expiração) a 3,31\% (lobo inferior, expiração). Conclusão: As margens adotadas na instituição foram consideradas adequadas em função dos resultados observados durante a movimentação do tumor na inspiração e na expiração máximas e em função da boa cobertura do PTV em relação aos GTV de inspiração e de expiração.

34

\section{Modelo em ratos Wistar para avaliação morfológica de efeitos cardíacos radioinduzidos}

Ribeiro AF 1,2, , Coimbra $\mathrm{AC}^{1,2,3}$, Andrade $\mathrm{CBV}^{2}$, Machado $\mathrm{SC}^{\prime}$,
Mandarim-de-Lacerda $\mathrm{CA}^{4}$, de Carvalho $\mathrm{JJ}^{2}$, de Almeida CE
'Laboratório de Ciências Radiológicas, ${ }^{2}$ Departamento de Histologia e Embriologia,
'Laboratório de Morfometria e Morfologia Vascular/
Universidade do Estado do Rio de Janeiro - Rio de Janeiro - (RJ)

Introdução: Segundo estimativas do INCA, aproximadamente 50.000 casos de câncer de mama foram diagnosticados em 2005. A teleterapia geralmente é escolhida em boa percentagem dos casos. A literatura indica que uma parte das mulheres pode desenvolver, num tempo médio de $5 \mathrm{a}$ 10 anos após o tratamento, cardiopatias radioinduzidas. Objetivo: Desenvolver um modelo radiobiológico em ratos Wistar para estudo dos efeitos cardíacos radioinduzidos. Métodos: Animais de ambos os sexos, com aproximadamente 3 meses, foram anestesiados com tiopental e irradiados em acelerador linear com feixe de fótons de energia nominal de 6MV. Foram administradas doses de 500cGy, 1000cGy e 1500cGy no volume cardíaco. Os ratos foram irradiados em posição supina, num campo de $3 \mathrm{~cm}^{2} \mathrm{X} 3 \mathrm{~cm}^{2}$. Os animais foram sacrificados após 2 dias, 15 dias e 4 meses da irradiação. O ventrículo esquerdo dos animais foi separado em material para microscopia ótica e para microscopia eletrônica de transmissão. Parte do material foi submetido a técnicas de imunoistoquímica. Resultados: Foi observado por microscopia ótica: infiltrado inflamatório no miocárdio e alteração de vasos sanguíneos (2dias e 15 dias) e algumas áreas de fibrose intramiocardica ( 4 meses), principalmente na regiāo perivascular. As alteraçōes observadas após 2 dias e 15 dias indicam o desencadeamento de uma resposta inflamatória, que pode culminar na liberação de citocinas pró-fibróticas, responsáveis por parte das cardiopatias radioinduzidas. As alteraçóes após 4 meses sugerem a geração de fibrose na área de maior acúmulo de lesóes iniciais. Apoio financeiro: FAPERJ e CNPq.

36 


\section{Radioterapia conformacional nos}

adenocarcinomas de próstata - experiência da Liga Norte Rio-Grandense Contra o Câncer

Gouveia NMD, Barros D, Santos EM, Najas RMFX, Menezes NA Liga Norte Rio-grandense Contra o Câncer (LNRCC) - (RN)

Introdução: $\mathrm{O}$ câncer de próstata é um tumor de alta prevalência e corresponde a segunda causa de óbitos por câncer em homens no mundo, sendo superado apenas pelo câncer de pulmão. A radioterapia é uma modalidade terapêutica com resultados semelhantes à cirurgia nas fases iniciais de apresentação e vem ganhando importância no tratamento em fases avançadas. Relatar os resultados terapêuticos dos adenocarcinomas de próstata tratados na Liga Norte Rio-grandense Contra o Câncer, no período de janeiro de 2002 a janeiro de 2004, com radioterapia conformacional - 3 D. Métodos: Análise retrospectiva de 91 pacientes portadores de adenocarcinoma de próstata, tratados no período de janeiro de 2002 a janeiro de 2004. Todos os pacientes foram planejados com tomografia computadorizada (TC Simulador) e sistema de planejamento 3D (CadPlan e SomaVision). Resultados: Foram analisados 91 pacientes com idade mediana de 71 anos. O PSA inicial variou de $4,4 \mathrm{ng} / \mathrm{mL}$ a $125 \mathrm{ng} / \mathrm{mL}$, com mediana de $13,7 \mathrm{ng} / \mathrm{mL}$. O escore de Gleason foi $\leq 6 \mathrm{em} 73$ pacientes $(80,21 \%)$; igual a 7 em 15 pacientes $(16,48 \%)$ e $>8$ em 3 pacientes (8,79\%). O estádio (TNM) foi T1 em 36 pacientes (39,56\%); T2 em 47 (51,64\%) e T3 em 8 (8,79\%); nenhum paciente era T4, N1 ou M1. Seguindo os critérios de risco sugeridos pelo "RTOG 9413", foram classificados em baixo risco 19 pacientes; em risco intermediário, 27 (29,67\%); e em alto risco 45 (49,45\%). Em relação à dose de tratamento: 2 pacientes $(2,19 \%)$ receberam menos de 70 Gy; 69 pacientes $(75,82 \%)$ receberam entre $70 \mathrm{~Gy}$ e $74 \mathrm{~Gy} ; 8$ pacientes $(8,79 \%)$ entre $74 \mathrm{~Gy}$ e $78 \mathrm{~Gy} \mathrm{e}$ 12 pacientes $(13,18 \%)$ receberam mais do que $78 \mathrm{~Gy}$. Texto truncado.

37

Avaliação dos danos em SNC causados pela radioterapia através da quantificação de transferência de magnetização

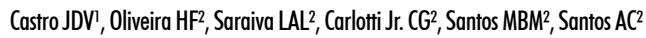
'Universidade Federal do Ceará - Fortaleza - (CE), ${ }^{2}$ Faculdade de Medicina de Ribeirão Preto da Universidade de São Paulo (FMRP-USP) - Serviço de Radioterapia (SERATE-USP) - (SP)

Introdução: Diversos estudos experimentais sustentam a teoria de desmielinização da substância branca cerebral normal (SB) em pacientes submetidos à radioterapia em sistema nervoso central (SNC). Porém, a avaliação e a quantificação desses danos carecem de métodos fáceis e fidedignos para utilização na prática clínica. Objetivo: Avaliar alteraçōes na SB provocadas pela radioterapia, utilizando índice de transferência de magnetização (MTR). Métodos: Estudo prospectivo, analisando 11 pacientes, idade média de 46,5 anos (33-68 anos), com diagnóstico de glioma invasivo, submetidos à radioterapia cerebral, com dose média de 6014cGy (5350-6600cGy), tratados no HC-FMRP-USP, no período de junho de 2002 a janeiro de 2005. Foram avaliados com ressonância magnética, aplicando pulso de transferência de magnetização a uma delas (MTnoSat e MTSat). Mapa foi gerado: MTR = (1 - [seqüência MTSat / sequência MTnoSat]) x 100. Medidas pré e pós-radioterapia (6-12 meses), através da seleção manual do corpo caloso inserido no volume irradiado, e não acometido pelo tumor e/ou cirurgia prévia. Os resultados foram analisados pelo teste de mediana de Wilcoxon. Resultados: Houve redução significativa do MTR do corpo caloso, em média de 7,13\%. O MTR pré e pós-radioterapia foi em média de 29,32 (32,07-25,54) e 27,23 (30,8622,05). Não houve diferença do MTR quanto à idade e à dose de tratamento. Conclusão: A quantificação de transferência de magnetizaçấo é método de ressonância magnética quantitativa capaz de detectar alteraçōes da SB após irradiação do SNC normal, conferindo análise não-invasiva confiável da toxicidade tardia provocada pela radioterapia.

39

\section{Avaliação imunológica em pacientes com} câncer de mama tratados com quimioterapia e radioterapia

Pinheiro AKDC, Cardoso AMS, Paiva MB, Santos EM, Najas RMFX Liga Norte Rio-grandense Contra o Câncer (LNRCC) - (RN)

Introdução: $\mathrm{O}$ câncer de mama é o segundo tipo de câncer mais freqüente no mundo e o primeiro entre as mulheres (cerca de 1 milhão de casos novos estimados). Os tratamentos concomitantes com quimioterapia e radioterapia melhoram a sobrevida e reduzem as metástases em pacientes com câncer, de acordo com a metanálise de ensaios clínicos. Pacientes portadores de doenças neoplásicas apresentam alta freqüência de anormalidades nos níveis sangüíneos. Objetivos: Avaliar a incidência de leucopenia nos pacientes atendidos na Liga Norte Rio-grandense contra o câncer (LNRCC), submetidos a tratamento de mama com radioterapia e quimioterapia. Investigar associaçōes entre deficiência imunológica, radioterapia e quimioterapia. Caracterizar a faixa etária de pacientes que apresentam deficiência imunológica desta população. Métodos: Trata-se de um trabalho retrospectivo, referente ao período de janeiro a dezembro de 2004, decorrente do levantamento do banco de dados com 96 pacientes portadores de câncer de mama histologicamente confirmados, após aprovação pelo Comitê de Ética em Pesquisa e obtenção do Consentimento Livre e Esclarecido dos participantes do estudo. Estas pacientes foram atendidas na LNRCC e submetidas a tratamento com RT+QT concomitante, antes ou após a cirurgia (conservadora ou radical). Todas as pacientes receberam a RT com dose total de 50,4Gy e, nos casos com indicação, boost de 10Gy. As drogas utilizadas na QT foram ciclofosfamida, methotrexato e 5-fluorouracil (CMF), Adriamicina e ciclofosfamida (AC) e 5-fluorouracil, adriamicina, ciclofosfamida (FAC). Texto truncado.

Respostas celulares ao estresse genotóxico causado pela radiação ionizante em linhagens de glioma proficientes e mutantes para o gene TP53

Godoy PRDV, Merchi IM, Sakamoto-Hojo ET

Introdução: Em células de glioblastoma, a heterogeneidade genética leva a uma sinalização celular alterada após o tratamento com raiosgama, diversificando as respostas entre tumores de diferentes pacientes. Objetivo: Analisar a sobrevivência celular e a expressão transcricional de genes de reparo do DNA (BRCA1 e PRKDC) e controle do ciclo celular (TP53 e ATM) em linhagens de glioblastoma, proficiente (U343) e mutante (T98G) para o gene TP53, submetidas à irradiação-gama. Métodos: A análise de sobrevivência celular (KIT XTT) foi efetuada 5 dias após a irradiação (2Gy, 4Gy, 8Gy e 16Gy), seguida da leitura colorimétrica em espectrofotômetro. O método de PCR quantitativa em tempo real foi utilizado para analisar a expressão dos genes $A T M$ e TP53, PRKDC e BRCA1, na dose de 4Gy e 8Gy. Resultados: Houve diferenças significativas, ao se analisar a sobrevivência celular, nas doses de 8Gy e 16Gy quando comparadas às duas linhagens, após a realização do teste t. Tanto os genes de ciclo celular quanto os de reparo que antes estavam reprimidos na menor dose foram induzidos na dose de $8 \mathrm{~Gy}$. No entanto a TP53 funcional não implica num aumento da mortalidade celular na linhagem U343. Esses fatores, associados a outras alterações genéticas intrínsecas das linhagens, podem conferir uma radiossensibilidade diferente, que não depende somente do status do TP53. 


\section{Construção de uma fonte de referência de} dosimetria, utilizando placa de $90 \mathrm{Sr}$ da rotina do serviço de radioterapia

Moreira MV, Farah AC, Pechevist PCD

Instituto de Radioterapia e Megavoltagem Ribeirão Preto - IRMEV - (SP)

Introdução: Devido às novas exigências da ANVISA/CNEN, os serviços de Radioterapia que não possuem uma fonte de 60Co devem realizar periodicamente as verificações de reprodutibilidade em seus medidores de radiação. Objetivo: O trabalho propōe a adaptação da fonte de $90 \mathrm{Sr}$ utilizada na rotina da betaterapia, em um contêiner de lucite e chumbo adaptado para receber o conjunto câmara de ionização-eletrômetro, e mostrar a eficiência em se utilizar uma fonte de referência através de um sistema com geometria ideal. Métodos: Utilizaram-se o eletrômetro CNMC 11 para as leituras de exposição e o cronômetro analógico para as medidas de tempo de exposiçáo, termômetro e o barômetro para as medidas de correção de temperatura e pressão. A fonte de ${ }^{90} \mathrm{Sr}+{ }^{90} \mathrm{Y}$ da Amersham SIQ $18 \mathrm{~N} 2244$ mede $4,0 \mathrm{~cm}^{2}$, atividade de $5,06 \mathrm{mCi}$, taxa de dose na superfície $1,56 \mathrm{cGy} /$ segundo e é emissora de partículas ß-com energia média de 2,2MeV. Resultados: São apresentados os valores de exposição na superfície do contêiner com a fonte, e à distância de $5,0 \mathrm{~cm}$ da superfície, e a geometria de aquisição dos dados. Conclusōes: $\mathrm{O}$ sistema de verificação de reprodutibilidade nas medidas de leituras é viável e necessita de ajustes de mediçôes tanto no setup da relaçâo câmara e fonte como no manuseio com o medidor de tempo, possibilitando a aplicação do PCQ com precisão. Os valores obtidos se mantiveram coerentes durante todo o período de testes, possibilitando ao serviço de Física Médica sua utilização na conferência da reprodutibilidade na avaliação da qualidade de medidas do sistema de dosimetria e dos limites de radioproteção, sendo que não ultrapassam aos sugeridos nos protocolos nacionais e internacionais de medidas.

41

\section{Diferentes técnicas de tratamento da fossa supraclavicular avaliadas por dosimetria termoluminescente}

Juliasz FS', Alencar MC1, Oliveira HF1, Galhardo EP1, Ghilardi Netto T', Costa AM² 'Serviço de Radioterapia, Hospital das Clínicas da Faculdade de Medicina de Ribeirão Preto (HCFMRP), ${ }^{2}$ Departamento de Física e Matemática, Faculdade de Filosofia, Ciências e Letras de Ribeirão Preto (FFCLRP), Universidade de São Paulo (USP),

Ribeirão Preto - (SP)

Introdução: Diversas técnicas de tratamento são empregadas na deposição da dose de radiação na região linfonodal da fossa supraclavicular (FSC). Objetivos: Avaliar a dose em linfonodos da FSC e região de medula espinhal, para duas diferentes profundidades de prescrição, utilizando dosimetria termoluminescente (TL) em objeto simulador antropomórfico (SA). Métodos: Leituras de 12 dosímetros TL LiF:Mg,Ti, utilizados após irradiaçóes em unidade de cobaltoteleterapia, Gammatron S-80 Siemens, no HCFMRP-USP. Irradiado SA em campo direto anterior em FSC bilateral. Dose de 1,8Gy foi prescrita no ponto de dose máxima (DM) e a $3 \mathrm{~cm}$ de profundidade (DP). TL foram colocados nas regiōes linfonodal da FSC e medula espinhal. Planejamento do SA em sistema de planejamento InterSoft (TPS) por tomografia computadorizada. Resultados: Para a irradiação DM, a FSC e medula receberam dose média igual a 1,30Gy e 1,08Gy, aferidas com TL e 1,35Gy e 1,06Gy com TPS, com diferença de $3,7 \%$. No cálculo DP, a dose média FSC foi de 1,47Gy para ambos os métodos. A dose em medula foi 1,18Gy e 1,14Gy, em TL e TPS, com diferença de 3,4\%. A deposição de dose linfonodos da FSC foi 11,5\% maior em DP quando comparado à DM, promovendo melhor cobertura desta região. Na técnica DP a dose na medula é 8,5\% maior. Conclusōes: Houve variação de dose, por diferentes técnicas, em regiôes de interesse no tratamento da FSC. Estas informaçōes auxiliam na elaboração de protocolos clínicos e contribuem para análises da resposta e padrōes de toxicidade.

\section{Verificação de dose em radioterapia de câncer} de cabeça e pescoço utilizando dosimetria termoluminescente

Juliasz FS', Alencar MC1, Galhardo EP', Oliveira HF', Nonato FBC2, Costa AM2 IServiço de Radioterapia, Hospital das Clínicas da Faculdade de Medicina de Ribeirão Preto (HCFMRP), 2Departamento de Física e Matemática, Faculdade de Filosofia, Ciências e Letras de Ribeirão Preto (FFCLRP), Universidade de São Paulo (USP),

Ribeirão Preto - (SP)

Introdução: No tratamento radioterápico do câncer de cabeça e pescoço (CCP), é essencial assegurar que as doses estejam sendo distribuídas apropriadamente, sendo este o objeto da dosimetria in vivo. Objetivos: Realizar estudo pré-clínico com mediçōes de dose de entrada e de saída (DES) em objeto simulador antropomórfico (SA) para a verificação do sistema de planejamento de tratamento (TPS), utilizando a técnica da dosimetria termoluminescente (TL) e estabelecer metodologia para dosimetria in vivo em radioterapia de CCP. Métodos: Utilizados 24 dosímetros TL LiF:Mg,Ti, irradiados em unidade de cobaltoteleterapia, modelo Gammatron S-80 Siemens. Estabelecido sistema dosimétrico TL por procedimento de inicialização, determinação da homogeneidade do lote, determinação da sensibilidade relativa intrínseca de cada dosímetro, determinação da faixa de linearidade do sistema e a determinação dos coeficientes de calibração da DES, utilizando-se uma câmara de ionizaçáo como instrumento de referência. Para a verificação do TPS, o SA foi irradiado utilizando-se campos paralelos e opostos látero-laterais em região cérvico-faciais e campo de fossa supraclavicular. O planejamento do SA incluiu uma tomografia computadorizada para cálculo de dose em sistema InterSoft. Avaliou-se em cada campo as DES. Considerou-se a dose na linha média igual à média entre a DES. Resultados: Nos campos látero-laterais, as diferenças das doses na linha média medidas e planejadas foram menores do que $0,44 \%$. Em FSC, a diferença da dose na linha média medida e planejada foi de $-2,4 \%$. Conclusôes: Os resultados mostraram a viabilidade da utilização da dosimetria TL para a verificação de dose em radioterapia de CCP no HCFMRP-USP. 42

Comparação da distribuição de dose para campos alargados e irregulares em acelerador linear de $10 \mathrm{MV}$

Alencar $M C^{1}$, Juliasz FS', Galhardo EP1, Oliveira HF', Soares $L S^{2}$, Costa AM² 'Faculdade de Medicina de Ribeirão Preto da Universidade de São Paulo (FMRP-USP) - Serviço de Radioterapia (SERATE-USP), ${ }^{2}$ Departamento de Física e Matemática da Faculdade de Filosofia, Ciências e Letras de Ribeirão Preto da Universidade de São Paulo (FFCLRP-USP) - Ribeirão Preto - (SP)

Introdução: $\mathrm{O}$ tratamento radioterápico pode envolver campos alargados e irregulares (CAI). Cálculo da distribuição de dose é determinado por método de Clarkson (MC) ou sistemas de planejamento tridimensional (TPS). Objetivo: Comparar resultados da distribuição de dose CAI, no ponto de prescriçãa e pontos fora do eixo central, utilizados na região infradiafragmática (RI) entre, (1) TPS; (2) MC; (3) dosímetros termoluminescentes (TLD); e (4) medidas de dosimetria absoluta (DA) com câmara de ionização (CI). Métodos: Pontos para análise da dose em RI, denominados centro do campo, ponto paraaórtico superior, paraaórtico inferior, hilo esplênico e hilo hepático. (1)Em TPS, realizado planejamento de campos paralelos e opostos ântero-posterior em objeto simulador virtual, homogêneo e de superfície plana. Cálculo TPS realizado em imagens e tomografia computadorizada em simulador antropomórfico onde foram selecionados os pontos de cálculo mencionados. (2)Com base nas radiografias digitalmente reconstruídas (DRR), aplicou-se $\mathrm{MC}$ nos pontos propostos. (3)Medidas TLD forma pastilhas, em capas de equilíbrio eletrônico. (4)Medidas CI em objeto simulador de água. Resultados: A análise evidencia desvios relativos abaixo de 2,6\%. Exceto em TPS, desvio de 2,9\% em paraaórtico superior; MC de 3,8\% em hilo hepático; TLD $3,2 \%$ em ponto central. Conclusōes: Os métodos de cálculo TPS, MC e medidas TLD apresentam valores semelhantes à DA. Possuem diferença relativa abaixo de $5 \%$ quando comparados à $\mathrm{DA}$, em concordância com valores da literatura; metodologia eficiente na avaliação do TPS e seu algoritmo de cálculo; a importância do uso de TLD, método eficiente de avaliação da dose.

44 


\section{Radioterapia conformacional em adenoma de hipófise: experiência do serviço de radioterapia do HC-FMRP-USP}

Amaral LL, Alencar MC, Juliasz FS, Barbi G, Trevisan FA, Oliveira HF Hospital das Clínicas da Faculdade de Medicina de Ribeirão Preto da Universidade de São Paulo (FMRP-USP) - Serviço de Radioterapia (SERATE-USP) - Ribeirão Preto - (SP)

Introdução: A radioterapia conformacional (RC) no tratamento de adenomas de hipófise $(\mathrm{AH})$ possui particularidades pela proximidade de estruturas normais e padrão de toxicidade. Objetivo: Analisar a RC e as características dos pacientes tratados no Serviço de Radioterapia do HC FMRP - USP com diagnóstico de AH. Métodos: Prontuários de 14 pacientes tratados com RC. Idade média 45,9 anos. Doze pacientes realizaram radioterapia pós-operatória. Doença supra-selar em $70 \%$. Sete pacientes apresentavam adenomas secretores. $64 \%$ apresentavam redução da acuidade visual prévia à RC. Além disso, $64 \%$ tinham diagnóstico de pan-hipopituitarismo anterior. Em TPS, foram analisados histogramas dose-volume (DVH) em volume-alvo planejado (PTV) e órgãos de risco incluídos. Resultado: Seguimento médio de 5,8 meses (0,3-15,4 meses); todos os pacientes permanecem vivos. Cinco pacientes apresentam ressonância magnética pós-radioterapia, intervalo médio de 6 meses, com manutenção das características tumorais. A dose total de tratamento variou 45Gy-54Gy, com dose biológica efetiva, média de 78,6Gy3 e 57,9Gy10. A duração média do tratamento foi 46,5 dias. Doze pacientes realizaram cinco campos de tratamento. Pacientes com doença supra-selar e restrito a sela, o PTV médio foi $17,2 \mathrm{~cm}^{3}$ e $11,4 \mathrm{~cm}^{3}$. Em média, a dose pontual em nervos ópticos foi 34,2Gy, quiasma óptico de 34,9Gy e dose média e pontual de tronco cerebral foi 2,1Gy e 45,3Gy. Conclusão: É mais prevalente a realização da radioterapia pós-operatória de tumores supraselar e após longo tempo da cirurgia; podendo determinar significativamente a dose depositada em tecidos normais e contribuir para o padrão de toxicidade encontrado.

45

Influência da colimação usada em campos de elétrons para a complementação de dose em região cervical posterior

Poli MER, Furnari L, Silva MA, Rubo R, Rodrigues LN, Yoriyaz H Radioterapia do Instituto de Radiologia do Hospital das Clínicas da Universidade de São Paulo (SP), Instituto de Pesquisas Energéticas e Nucleares - IPEN/CNEN - (SP)

Introdução: Uma das técnicas alternativas para se tratar a região cervical posterior com doses superiores a $50 \mathrm{~Gy}$ em cânceres da região da cabeça e pescoço é a utilização de feixes de elétrons para que a medula espinhal não receba dose superior a 50Gy. A característica do feixe de elétrons pode variar dependendo da forma do campo e outros fatores. Objetivo: Investigar o comportamento de feixes de elétrons em campos colimados. Métodos: Foram utilizados dois sistemas: filme X-Omat V e câmara de placas paralelas. As medidas foram realizadas num fantoma $30 \times 30 \times 30 \mathrm{~cm}^{3}$ com suporte próprio para segurar o filme dentro da água em posição vertical, e outro para manter a câmara paralela à superfície da água. Eles foram irradiados com feixes de $6 \mathrm{MeV}, 9 \mathrm{MeV}, 12 \mathrm{MeV}$ e $15 \mathrm{MeV}$; cone $15 \mathrm{~cm}^{2} \times 15 \mathrm{~cm}^{2}$ com bandeja padrão (cone 15) e bandeja própria para irradiar o cervical posterior. Os dados de planura e rendimento foram obtidos para a distância foco-superfície (DFS) de $100 \mathrm{~cm}$ e $110 \mathrm{~cm}$ nas profundidades de $R_{100}, R_{85}, R_{50}$ e na superfície do fantoma. Resultados: Verificou-se uma diminuição de dose entre $19 \%$ e $20 \%$ para medidas de rendimento com DFS de $100 \mathrm{~cm}$ para $110 \mathrm{~cm}$. As medidas de PDP, usando a colimação de cervical em relação ao cone 15 , mostraram um aumento da dose próxima à superfície de até $5 \%$ e, após a região de build-up, uma diminuição da PDP em até $3 \%$ em relação à colimação padrão. Texto truncado.
Como reduzir os custos financeiros de um serviço de radioterapia em uma oficina de moldagem

\section{Menezes JS', Filho HS', Santos FA', Santos WM', Silveira MAL'2 'Hospital Governador João Alves Filho (Setor de Física Médica), ${ }^{2}$ Departamento de Física da Universidade Federal de Sergipe - UFS - (SE)}

Introdução: Os custos financeiros dos tratamentos radioterápicos são elevados, e decorrem dos altos custos dos equipamentos utilizados. Muitas das atividades desenvolvidas no planejamento radioterápico são realizadas em uma oficina de moldagem dos serviços de radioterapia. Objetivos: Apresentar os procedimentos que podem ser utilizados na redução dos custos financeiros dos tratamentos radioterápicos, em uma oficina de moldagem dos serviços de radioterapia. Métodos: Após a confecção dos moldes em isopor, a liga de "cerrobend" é despejada para a confecção dos blocos de proteção. Para corrigir imperfeiçōes, os blocos são limados sobre uma gaveta para recolhimento do pó, que é fundido e reutilizado na confecção de outras proteções. De modo semelhante, os retraços de isopor são cortados, colados e reutilizados nas moldagens de novos blocos. As máscaras termoplásticas, utilizadas na imobilização dos pacientes, que perderam elasticidade após o seu uso são reutilizadas, depois da recomposição das partes sem elasticidade. Resultados: Com o pó e os pequenos pedaços de "cerrobend" recolhidos obtiveram-se blocos de pesos iguais a $6,8 \mathrm{~kg}$ e $23,6 \mathrm{~kg}$. As máscaras termoplásticas reaproveitadas mantiveram o seu poder de imobilização e os retraços de isopor, colados, produziram blocos de qualidade igual às das folhas novas de isopor. Conclusóes: As máscaras termoplásticas recuperadas, o pó de "cerrobend" resultante das limagens dos blocos de proteção dos órgãos críticos e o reaproveitamento dos retraços dos isopores podem minimizar os elevados custos do tratamento radioterápico.

Cálculo de Monte Carlo para a determinação da atividade de fonte de 192Ir imersa em Solução Fricke

Sibata $\mathrm{C}^{1}$, Austerlitz $\mathrm{C}^{1}$, Mota $\mathrm{H}^{1}$ e Sempau J2

'The Brody School of Medicine at ECU, Radiation Oncology Department - Greenville, NC (USA), ${ }^{2}$ Universitat Politecnica de Catalunya, INTE - Barcelona, (Espanha)

Cálculos de Monte Carlo foram feitos para determinar a relação entre a dose absorvida média recebida por uma solução Fricke e a atividade de uma fonte de 192Ir imersa nessa solução. As simulações foram feitas com o código de Monte Carlo Penelope, variando-se a espessura da parede do tubo que guia a fonte, o diâmetro do cilindro de PMMA que contém a solução Fricke e o posicionamento da fonte ao longo do eixo longitudinal desse cilindro. Os resultados das simulações demonstraram que: (a) a dose absorvida média no volume total da solução Fricke é bastante dependente do raio do cilindro, praticamente independente da espessura do tubo e independe do posicionamento da fonte em relação ao centro geométrico do volume do detector; (b) a dose absorvida na região próxima ao tubo de PMMA apresenta uma certa dependência com a espessura do tubo de PMMA e= (c) para o sistema dosimétrico estudado, o coeficiente entre a dose absorvida média no Fricke e a atividade da fonte radioativa foi $0,55676 \mathrm{cGy} / \mathrm{Ci}$, com um erropadrão de $0,02 \%$. Foi concluído que a técnica de $\mathrm{MC}$ pode ser utilizada para tornar tal sistema de dosimetria Fricke absoluto e com dimensão tal que a relação $\mathrm{cGy} / \mathrm{Ci}$ seja unitária. 


\section{Paracoccidiodomicose linfático-abdominal simulando neoplasia primária das vias biliares}

Gontijo CCV, Prado FLS, Prado RS, Neiva CLS, Pedroso ERP Centro de Treinamento e Referência em Doenças Infecto-Parasitárias (CTR-DIP) da Faculdade de Medicina da Universidade Federal de Minas Gerais Belo Horizonte - (MG)

Introdução: A forma abdominal da paracoccidiodomicose leva a um acometimento extenso e generalizado, podendo produzir quadros clínicos diversos, como alteração no ritmo intestinal, náusea, vômito, ascite, icterícia, dor abdominal, hepatoesplenomegalia, massa tumoral, obstrução intestinal e peritonite. Aqui é relatado o problema de um paciente com paracoccidioidomicose crônica, que evoluiu com colestase simulando neoplasia primária das vias biliares. Relato de Caso: A.M.S., 44 anos, feminino. Hígida até 1993, quando iniciou com linfadenomegalia cervical, submandibular e axilar, astenia, febre, emagrecimento $(4 \mathrm{~kg})$ e lesão exulcerada em palato mole, cuja biopsia revelou a presença de Paracoccidioides brasiliensis. No início de 1999, apresentou reagudização do quadro, evoluindo com mal estar, vômitos, dor em hipocôndrio direito e epigástrio, icterícia, colúria e acolia fecal. A paciente foi internada no HC da UFMG para propedêutica. A ultra-sonografia abdominal revelou moderada dilatação de vias biliares intra-hepáticas e massa amorfa sugestiva de aglomerado linfonodal em hilo hepático, além de lesōes focais esplênicas. A paciente recebeu anfotericina $B$ endovenosa por 12 dias com melhora dos sintomas e do quadro colestático. Até sua última consulta (18/09/05), a paciente encontrava-se estável. Discussão: A tumoração abdominal pode ser um dos achados clínicos na PCM. Essas massas são descritas na literatura como móveis, raramente aderidas, contorno irregular, consistência firme, múltiplas, de tamanhos variados, podendo-se palpar grandes massas que são linfadenomegalias.

Texto truncado.

49

\section{Dose testicular durante radioterapia} conformacional em 3 dimensões (RTC3D) de câncer de próstata (CAProst)

\author{
Mendonça LM, Hashimoto MH, Seixas C, Viegas CMP, Araúio CM \\ Seção de Radioterapia do Instituto Nacional de Câncer - Rio de Janeiro - (RJ)
}

Introdução: RTC3D é a técnica desenvolvida para administrar localizada e precisamente radiação ao tumor e restringi-la em tecidos normais adjacentes. Maiores doses são relacionadas a aumento de controle tumoral e complicações. Testículos desprotegidos podem receber até $8 \%$ da dose administrada. Relatos indicam toxicidade gonadal com doses variáveis: infertilidade temporária com 15 cGy e permanente com 300-600cGy em experimentos in vitro; $65 \mathrm{cGy}$ para a primeira situação e $200 \mathrm{cGy}$ para a segunda, em ensaios in vivo. Objetivo: Quantificar a dose recebida com RTC3D pelos testículos em fantoma, em campo simulado de CAProst, com e sem uso da blindagem testicular. Métodos: Foi realizada dosimetria em fantoma antropomórfico (Rando-Alderson), tendo a topografia testicular como parâmetro-alvo. Utilizaram-se 4 campos de irradiação (AP-PA / LL). Foram revisados os últimos 12 casos programados no serviço. Calcularam-se um campo equivalente para cada campo de tratamento e uma média do tamanho de campo e posicionamento do isocentro. Para os campos ântero-posterior e póstero-anterior, o tamanho encontrado foi de $7,7 \mathrm{~cm} 2 \times 7,7 \mathrm{~cm}^{2}$. Para os campos laterais de $7,0 \mathrm{~cm} 2 \times 7,0 \mathrm{~cm}^{2}$. Utilizaramse câmara de ionização com "build up" de 3,0cm e energia de $15 \mathrm{MV}$. Os planejamentos dos tratamentos foram baseados em imagens tomográficas. Resultados: Cinco irradiaçôes foram realizadas para cada campo de tratamento, sendo depois feita média de dose encontrada em topografia testicular. As doses de tratamento utilizadas foram de 72Gy em 36fr. A dose final em topografia testicular sem uso da blindagem foi de 90cGy e com uso, 30cGy.

51

\section{Câncer de testículo: dose testicular na irradiação abdominopélvica e paraaórtica}

Mendonça LM, Hashimoto MH, Seixas C, Viégas CMP, Araújo CM

Seção de Radioterapia do Instituto Nacional de Câncer - Rio de Janeiro - (RJ)

Introdução: São tratamentos aceitáveis para pacientes com seminoma clássico: vigilância e radioterapia pélvica (RTPelv) e/ou paraaórtica (RTPA) em pacientes estádio I. Relatos indicam toxicidade gonadal com doses variáveis: infertilidade temporária com 15cGy e permanente com 300-600cGy em experimentos in vitro; 65 cGy para a primeira situação e $200 \mathrm{cGy}$ para a segunda em ensaios in vivo. Objetivo: Verificar a dose testicular recebida em fantoma após utilizaçâo de campos de RTPA com ou sem RTPelv, utilizando ou não blindagem. Métodos: Realizaram-se medições em fantoma antropomórfico (Rando-Alderson) com parâmetros anatômicos, determinando as delimitaçốes de campos ântero-posteriores de RTPA - limite superior entre T10/T11, inferior L5/S1, e RTPA + RTPelv com limite superior entre T9/T10 até a articulação sacroilíaca inferior e campo pélvico ipsilateral ao tumor. Foram usadas câmara de ionização, com "build up" de $1,5 \mathrm{~cm}$ e avaliaçōes com e sem uso da blindagem testicular. Os planejamentos foram baseados em imagens tomográficas e irradiou-se o fantoma com energia de 6MV. As doses utilizadas foram de $30 \mathrm{~Gy}$ em $18 \mathrm{fr}$ e $25 \mathrm{~Gy}$ em $15 \mathrm{fr}$. Resultados: A dose final em topografia testicular sem blindagem foi 0,089Gy e 0,074Gy para cada dose-padrão utilizada com RTPA e $0,164 \mathrm{~Gy}$ e $0,137 \mathrm{~Gy}$ em RTPA+RTPelv. Após uso da proteção testicular, reduziu-se a dose para $0,042 \mathrm{~Gy}$ e $0,035 \mathrm{~Gy}$ e $0,070 \mathrm{~Gy}$ e $0,042 \mathrm{~Gy}$, respectivamente. Conclusão: Sempre que possível deve-se utilizar proteção testicular devido à presença da contribuição de dose por espalhamento ou fuga do cabeçote. Apesar de as doses verificadas não ultrapassarem às relatadas para esterilidade transitória, deve-se ressaltar a grande variaçãa na quantificação desse tipo de dose. Testes in vivo de pacientes permitirāo a confirmação dos resultados. 50

\section{Braquiterapia de alta taxa de dose no tratamento de tumor de colo uterino com envolvimento vaginal distal e resposta completa à radioterapia externa: qual a dose e a extensão vaginal necessárias no tratamento?}

Castilho MS, Guimarães FS, Jacinto AA, Arruda GV, Fagundes LA, Novaes PERS, Salvajoli JV

Introdução: A literatura é inexistente em relação à dose necessária de Braquiterapia de Alta Taxa de Dose (BATD) no tratamento da vagina após resposta completa à radioterapia externa (RTE) no câncer de colo. Métodos: De 1993 a 2001, 24 pacientes com comprometimento vaginal médio-inferior apresentaram resposta completa vaginal após RTE. Cinco ECIIIA, 19 ECIIIB com envolvimento vaginal. Sete pacientes receberam BATD com sonda intra-uterina e cilindros vaginais por 4 inserçōes (toda a vagina com a mesma dose), e 17 alternaram cilindros e ovóides (gradiente de dose na vagina). Resultados: Seguimento mediano 49 meses. Sobrevidas global, câncer específica, livre de recidiva e livre de recidiva vaginal em 5 anos: $53 \%, 60 \%, 68 \%$ e $81 \%$, respectivamente. Recidivas vaginais: $14 \%$ versus $18 \%$ para as pacientes que não alternaram versus as que alternaram os aplicadores $(\mathrm{p}=0,67)$. Efeitos adversos vaginais $71 \%$ vs $53 \%$. Conclusões: Pacientes com resposta completa vaginal após RTE representam um grupo de melhor prognóstico quando comparadas a controles históricos. Alternância dos aplicadores produziu taxas similares de controle local e vaginal quando comparada com o tratamento de toda a vagina até a dose final prescrita. O controle vaginal é autoindependente do esquema de tratamento $(81 \%)$. O potencial de efeitos adversos em vagina, reto e bexiga pode ser inferior. 


\section{Análise do sistema de tratamento de malformação arteriovenosa com radiocirurgia}

Hashimoto MH, Oliveira OR, Nakashima JP, Batista DVS, Bardella LH Instituto Nacional de Câncer - Rio de Janeiro - (RJ)

Introdução: Malformação arteriovenosa cerebral (MAV) é caracterizada pela ausência de vasos de resistência entre as artérias e veias. Decorre de erros no desenvolvimento da vasculatura cerebral com aglomerados anormais de artérias. Radiobiologicamente, a MAV encontra-se na categoria de tecidos de resposta tardia. A radiocirurgia estereotáxica permite acurácia na entrega de altas doses em alvos pequenos intracranianos bem localizados (MAV), consistindo na aplicação de uma dose única e elevada de radiação. Objetivos: Avaliar e quantificar os erros associados a esta técnica de tratamento que está disponível no sistema de planejamento do Hospital do Câncer I do Instituto Nacional de Câncer. Método: Foi utilizado um simulador de cabeça oco, preenchido com arroz; uma esfera de acrílico para simular a lesão; e um filme como dosímetro. Nesta cabeça foi colocado um frame estereotático e uma caixa localizadora. Foram feitas duas radiografias: ântero-posterior e látero-lateral, e uma tomografia computadorizada. Os filmes foram escaneados e as imagens do CT e das radiografias foram importadas para o software de radiocirurgia onde foi realizada a fusão das imagens. O objeto simulador foi irradiado num acelerador linear com feixe de fótons de $6 \mathrm{MV}$ e cone de $30 \mathrm{~mm}$ de diâmetro e uma dose de $210 \mathrm{cGy}$. Resultado: O filme irradiado apresentou um desvio de $0,7 \% \mathrm{da}$ dose prescrita. Conclusão: A dose entregue no centro da esfera mostra a precisão no cálculo do sistema e ajuda a comprovar que esta técnica pode ser considerada segura e hábil para o tratamento da MAV.

53

Cuidados de radioterapia em paciente com obesidade mórbida e adenocarcinoma de endométrio

Nakashima J, Maeda IA, Viégas CMP, Otano S, Valdivino D, Araúijo CMM Seção de Radioterapia do Instituto Nacional de Câncer- Rio de Janeiro - (RJ)

Introdução: A obesidade é um dos fatores de risco para adenocarcinoma de endométrio (ACaEndo). O tratamento consiste em cirurgia radical, seguida de radioterapia externa (RT) e braquiterapia vaginal (BQT), dependendo dos achados. Pacientes com obesidade mórbida (OM) freqüientemente não sofrem a cirurgia-padrão. RT nestes casos é desafio ao especialista. Objetivos: Descrever cuidados com paciente pesando $167 \mathrm{~kg}$ submetida à RT no Serviço de Radioterapia do INCA. Relato do caso: Mulher de 66 anos foi submetida à histerectomia vaginal em 9/05/06 com laudo de ACaEndo, grau 2. Estadiada como FIGO IIIB G2, cirurgia nãooncológica e margens vaginais comprometidas. Em decúbito ventral, DAP, $38 \mathrm{~cm}$ e DLL, $66 \mathrm{~cm}$. A programação ocorreu em duas dimensões no Serviço de Radiologia. Contrastou-se o reto com bário e posicionou-se o marcador radiopaco no limite inferior da doença vaginal. Tomaram-se duas exposiçōes radiográficas, a primeira, com campo pélvico de tratamento e a segunda, com campo aberto. Marcaram-se limites de localização lateralmente no quadril, pela projeção dos $L A S E R S$ verticais do aparelho de tratamento. Tratamento: Deslocou-se a mesa do acelerador linear Varian-Clinac $2300 \mathrm{C} / \mathrm{D}$ a $90^{\circ}$ e utilizou-se maca convencional móvel. Adotou-se mudança de decúbito, com distâncias fonte-superfície distintas: $116,0 \mathrm{~cm}$ e $119 \mathrm{~cm}$ (anterior e posterior, respectivamente). Prescreveram-se 45Gy/25 fraçôes sobre pelve, linha média, com energia de 15,0MV. Realizaram-se portais semanais.

Texto truncado.

\section{Perfil dos atendimentos de radioterapia de urgência no Instituto Nacional de Câncer (INCA)}

Osório LS, Maia MS, Viégas CMP, Araújo CMM Seção de Radioterapia do Instituto Nacional de Câncer - Rio de Janeiro - (RJ)

Introdução: Grande parte dos pacientes oncológicos no Brasil apresenta estádios avançados, levando à necessidade de radioterapia paliativa. Objetivo: Realizar o perfil de atendimento dos pacientes encaminhados para radioterapia de urgência (RTUrg) no Serviço. Métodos: Os pacientes foram cadastrados em um banco de dados, sendo analisados os seguintes fatores: dia da semana mais freqüente de encaminhamento, sítios primários envolvidos, locais mais freqüentemente tratados e doses utilizadas. Resultados: De janeiro a junho de 2006, 180 pacientes foram encaminhados. Os dias de maior freqüência de encaminhamento foram segundas-feiras $-2^{\text {as }}$ feiras $(23 \%)$, seguidos por quintas-feiras $-5^{\text {as }}$ feiras $(20 \%)$ e sextas-feiras - $6^{a s}$ feiras (19\%). Metástase óssea representa a maioria (37\%) dos casos, seguida por síndrome de compressão medular (SCM) (18\%) e metástase cerebral (14\%). O câncer primário mais freqüente foi pulmão (33\%), seguido por mama (14\%). Os esquemas mais utilizados foram 800 cGy/ 1 fração para doença óssea $(69 \%), 2000$ cGy $/ 5$ fraçōes para metástase cerebral (58\%) e para SCM (48\%). Conclusão: Contrariando nossa expectativa, $2^{\text {as }}$ foram os dias de maior encaminhamentos, provavelmente devido a ser o primeiro dia de atendimento após o fim de semana, após atualização das evoluçōes clínicas. Maior índice de encaminhamento de $5^{\text {as }}$ comparados aos de $6^{\text {as }}$ deve-se provavelmente aos feriados ocorridos neste último dia, no primeiro semestre de 2006. Empregamos com frequiência doses únicas pela expediência e comodidade para o paciente.

Texto truncado.

54

\section{Planejamento radioterápico com campos moduladores para o câncer de mama}

\author{
Rodrigues JL, Caballero KCS, Santos MA, Fonseca MR \\ Hospital Santa Lúcia - Braślia - (DF)
}

Introdução: $\mathrm{O}$ tumor maligno de maior incidência no sexo feminino éo carcinoma mamário. A radioterapia tem se mostrado uma ferramenta eficiente na luta contra esse tipo de câncer, principalmente devido aos recentes avanços nas técnicas de planejamento 3D, visando a poupar tecido sadio. A radioterapia convencional da mama determina um alto gradiente de dose por não contabilizar fatores como a mudança na geometria do contorno da mama, condiçōes propícias às CTN. Objetivos: $\mathrm{O}$ trabalho tem por objetivo prevenir as CTN sem comprometer a probabilidade de controle do tumor através da avaliação do diâmetro mamário, histograma dose-volume e a razão terapêutica. Métodos: A idade média dos pacientes estudados foi de 54 anos para um padrão de dose de 50,4Gy em 28 seçôes. Todos os pacientes foram submetidos à CT de tórax. Os órgãos críticos foram delineados e o HDV permitiu avaliar o volume de tecido crítico para a introdução dos campos moduladores. Resultados: Mamas com diâmetros maiores do que $23,5 \mathrm{~cm}$ e com volume $6 \mathrm{~cm}^{3}$ ou mais, recebendo dose acima de $110 \%$, apresentaram dermatite entre a $3^{\text {a }}$ e a $5^{\text {a }}$ semanas de tratamento. Razóes terapêuticas menores do que $8,0 \%$ após modulaçáo mostram-se mais eficientes para o controle das CTN; quando ela é maior do que $10 \%$, mas com volume envolvido menor do que $2 \mathrm{~cm}^{3}$, o controle também é eficiente. Conclusóes: A modulaçáo dos campos na radioterapia de mama reduz a probabilidade de complicações em tecido sadio, mostrando ser uma alternativa viável à técnica de IMRT. 


\section{Avaliação retrospectiva da eficácia da radioterapia como segunda linha neo-adjuvante em pacientes com câncer de mama localmente avançado que falharam ao tratamento primário com antraciclínicos}

Melo AC, Gaui MFD, Biasoli I, Spector N

Instituto Nacional de Câncer - Rio de Janeiro - (RJ)

Introdução: $\mathrm{O}$ câncer de mama localmente avançado representa no Brasil cerca de $30 \%$ dos tumores de mama. A quimioterapia baseada em antraciclínicos é o tratamento padrão. A literatura revela que cerca de 1/3 das pacientes não responderão ou permanecerão inoperáveis após a primeira linha. Os dados são escassos em relação ao uso de radioterapia nos casos refratários à quimioterapia com antraciclínicos. Objetivos: Avaliar a resposta à radioterapia como segunda linha em pacientes com câncer de mama localmente avançado que falharam ao tratamento com antraciclínicos, analisando a operabilidade e a resposta patológica. Métodos: Análise retrospectiva do uso da radioterapia em pacientes com câncer de mama localmente avançado que falharam aos antraciclínicos. Foram elegíveis as pacientes inoperáveis que não responderam ou que tiveram pequena resposta aos antraciclínicos, permanecendo inoperáveis, no período entre 2000 e 2002. Todas foram submetidas à radioterapia externa na mama, com 50Gy em 5 semanas. Quatro semanas após a radioterapia, foram reavaliadas visando à cirurgia: as operáveis foram submetidas à mastectomia e as que permaneceram inoperáveis foram tratadas paliativamente. A sobrevida global e a sobrevida livre de doença foram calculadas pelo método de Kaplan-Meier. Resultados: Foram analisadas 38 pacientes com CDI localmente avançado inoperáveis. Após o tratamento com radioterapia, 23 pacientes $(60 \%)$ anteriormente consideradas inoperáveis realizaram a mastectomia. A sobrevida global mediana de todas as pacientes foi de 27 meses (IC 95\%: 25,6-34,8); a sobrevida livre de doença mediana foi de 12,6 meses (IC 95\%: 6,1-18,7); e a sobrevida livre de progressão 17,8 meses (IC 95\%: 14,4-21,1). Texto truncado. 57

\section{Cutaneous metastasis from renal cell carcinoma: a case report}

Cavalieri $\mathrm{R}^{1}$, Gay $\mathrm{H}^{2}$, Allison $\mathrm{R}^{2}$ IInstituto Nacional de Câncer - Rio de Janeiro - (RJ) ${ }^{2}$ Department of Radiation Oncology, The Brody School of Medicine at East Carolina University, Greenville, NC (USA)

Introduction: Cutaneous metastases from solid primary tumors are uncommon, and by the time these present, the disease is usually widespread. Objective: We report a patient who presented with a single cutaneous lesion on his face which was treated with radiotherapy. Case Report: A 51-year-old man presented with a metastatic renal cell carcinoma in December of 2004. He received interleukin-2 from 2/14/2005 through $07 / 25 / 2005$. Despite treatment, his disease progressed, and he developed a single pulsatile purplish lesion on the skin of the left face measuring $2 \mathrm{~cm}$ $\mathrm{x} 2 \mathrm{~cm}$. A skin biopsy was consistent with metastatic renal cell carcinoma. He was treated between $9 / 29 / 2005$ and $10 / 25 / 2005$ with a single direct $14 \mathrm{MeV}$ electron field in 14 fractions of $375 \mathrm{cGy}$. The patient tolerated therapy without difficulty. On 11/17/2005 the patient was enrolled in a protocol with Sorafenib, an oral dual-action Raf kinase and vascular endothelial growth factor receptor (VEGFR) inhibitor. He was not consistently compliant with the Sorafenib therapy. By $1 / 5 / 06$, the patient had a complete clinical response. He has been evaluated and there is no evidence of recurrence as of 7/3/06. Discussion: This case demonstrates an uncommon manifestation of renal cell carcinoma palliated with an aggressive radiotherapy approach. Reports of radiation therapy for this kind of lesion are rare. In our case, the patient achieved an excellent palliation with the treatment after 2 months. Conclusion: Our case shows that aggressive radiation therapy can result in excellent palliation, and complete tumor regression is a slow process that takes various months.

\section{Câncer de mama em homens:}

análise de 66 casos

Cavalieri R, Faroni L, Erlich F, Rodrigues M, Mendonça L, Gama MP, Viégas CM, Araújo CMMInstituto Nacional de Câncer - Rio de Janeiro - (RJ)

Introdução: Câncer de mama é raro em homens, correspondendo a 1\% dos casos. O tratamento atual deriva do seu correspondente feminino. Objetivos: Analisar aspectos epidemiológicos, clínicos, diagnósticos e terapêuticos em 66 casos atendidos no Instituto Nacional de Câncer (INCA). Resultados: Com seguimento mediano de 18,7 meses, a idade média dos pacientes foi 62 anos. Eram brancos 69,7\%. Queixa principal foi nódulo indolor (72,7\%) e tempo médio entre sintomatologia e diagnóstico foi 17,2 meses. Histologia mais freqüentemente foi (CDI) $(80,3 \%)$. Linfonodos (LN) foram avaliados em 31 pacientes $(47 \%)$, sendo isolados em média 15,7 , com comprometimento em $71 \%$ dos casos. O número médio de $\mathrm{LN}$ positivos foi 7,9. Estádios avançados foram freqüentes (IIIB, 37,3\% e IV, 28,8\%). Tratamento radical ocorreu em 33 casos (50\%); paliativo, em $26(39,4 \%)$ e $7(10,6 \%)$ não receberam tratamento. No grupo radical, todos foram mastectomizados, sendo que 31 (94\%) receberam quimioterapia e 17 (51\%) radioterapia (RT). Dose mais freqüente foi $50 \mathrm{~Gy} / 25$ fraçóes e foi dirigida ao plastrão $(\mathrm{P})$, fossa $(\mathrm{F})$, axila $(\mathrm{A})$, e mamária interna em 2 casos (11,7\%); a PFA em 6 (35,3\%); PF em 2 casos (11,7\%), somente plastrão em 7 casos $(41,2 \%)$. A sobrevida média foi 5,9 anos, sendo que os pacientes que receberam cirurgia e RT viveram 7,9 anos. No grupo paliativo, 6 pacientes (18\%) foram operados, e 19 receberam RT $(57,5 \%)$, com dose de 20Gy/5 fraçóes em 10 casos sobre sítios metastáticos, com sobrevida média de 1,8 anos. Conclusão: Pacientes masculinos com CAMA apresentam-se com doença avançada. RT desempenha papel fundamental no tratamento curativo desses pacientes.

Radioterapia com intensidade modulada (IMRT) em câncer de colo uterino: regressão e mobilidade tumoral

Cavalieri RV', Bezerra ML', Valdivino D', Viégas CMP', Araújo CMM', Patury P2.
Seçãao de Radioterapia 'e Ginecologiaª do Instituto Nacional de Câncer Rio de Janeiro - (RJ)

Introdução: Radioterapia em câncer de colo uterino (CCC) localmente avançado é padrão. IMRT permite minimizar toxicidade, porém desconhece-se o grau de mobilidade tumoral. Objetivos: Avaliar a regressão e a mobilidade tumoral durante IMRT de paciente com CCC, comparando-as à radioterapia convencional (RTConv). Métodos: Analisaram-se planejamentos de paciente com CCC, estágio clínico IIIB com IMRT e RTConv. CTV primário (CTV1) foi vagina proximal, paramétrios e útero. Delineação dos linfonodos foi realizada pelas diretrizes do ASTRO criando-se o CTV linfonodal (CTVLinf). Volume-alvo de planejamento (PTV) foi a soma do CTV1 com CTVlinf e margem tridimensional de $1 \mathrm{~cm}$. Órgãos de risco foram bexiga, intestinos e reto. Prescreveu-se a dose de $45 \mathrm{~Gy}$. Avaliaram-se a regressão e a mobilidade tumoral por RM aos 21,6Gy e 30,6Gy. Obteve-se um novo CTV1 para cada momento do tratamento. Resultados: Os volumes do CTV1, $\mathrm{CTV}_{21.6}$.e $\mathrm{CTV}_{30.6}$ foram respectivamente $215,8,158$, e $153 \mathrm{~cm}^{3}$. Os volumes dos CTV cobertos pela dose prescrita foram: 94,8\% aos 21,6Gy e 99\% aos 30,6Gy. Após 21,6Gy e 30,6Gy, houve redução no volume do CTV1, respectivamente, de $26,5 \%$ e $29 \%$. O maior deslocamento do CTV1 ocorreu ao nível do fundo uterino, ântero-posteriormente, havendo desvio de 3,3cm entre o CTV1 e CTV ${ }^{21.6}$ e 2,8cm entre o CTV1 e $\mathrm{CTV}_{30,6}$. Comparando-se RTConv à IMRT, os valores de V30 para reto e intestinos e V40 para bexiga foram, respectivamente $95 \%$ x $71 \% ; 72 \%$ x 52\%, 100\% x 48,5\%. Conclusóes: IMRT apresentou vantagens em relação à RTConv. Imagens seriadas são importantes na avaliação e determinação das margens.

60 


\section{Correlação entre achados de ressonância} magnética pélvica pré-operatória e peça cirúrgica em pacientes com neoplasia de colo uterino: estudo preliminar

Barbieri RC, Justino PB, Carvalho HA, Stuart SR, Blasbalg R, Carvalho FM, Carvalho JP Serviço de Radioterapia Hospital das Clínicas da FMUSP - São Paulo - (SP)

Introdução: A ressonância magnética (RM) tem demonstrado alta sensibilidade e especificidade no estadiamento de neoplasias do colo uterino. Além disso, seus achados têm trazido importante contribuição para o planejamento da radioterapia. Em nosso meio, no entanto, a experiência é ainda restrita e a confiabilidade do método não está bem definida. Objetivos: Avaliar a concordância dos achados da ressonância magnética pré-operatória com o resultado da cirurgia em tumores de colo uterino. Métodos: Foram analisadas 9 pacientes com diagnóstico histológico de neoplasia de colo uterino. Em 5 casos, o tipo histológico foi carcinoma de células escamosas; em 3 foi adenocarcinoma e 1 caso com carcinoma adenoescamoso. Todas estavam em estádio clínico I. Foi realizada ressonância magnética pré-operatória da pelve para a complementação do estadiamento, seguida de cirurgia radical (pan-histerectomia com linfadenectomia bilateral -Wertheim-Meigs). Os parâmetros analisados foram o maior diâmetro do tumor, invasão de paramétrios, invasão de vagina, extensão para o corpo uterino e presença de linfonodos pélvicos comprometidos. Resultados: Nas 9 pacientes, os achados da RM foram concordantes com os da cirurgia. Conclusôes: Até o presente momento, a RM demonstrou $100 \%$ de sensibilidade na avaliação pré-operatória dos carcinomas de colo uterino estádio Ib. O estudo está em continuação para melhor avaliar a sensibilidade e a especificidade do exame.

61

Verificação da função de anisotropia da fonte de ${ }^{192}$ Ir utilizada pelo sistema de planejamento de braquiterapia

Zangrandi ML, Bardella LH, Batista DV Instituto Nacional de Câncer - Rio de Janeiro - (RJ)

Introdução: A determinação da taxa de dose de uma fonte usada em braquiterapia, em um meio espalhador, torna-se importante, pois verifica os algoritmos de cálculo utilizados em sistemas de planejamento. O formalismo de cálculo disponível nos Reports $\mathrm{n}^{\circ}$ 51 e nº 84 da AAPM, que propõe o cálculo da distribuição de dose de uma fonte através de seus parâmetros dosimétricos. Objetivos: Obter função de anisotropia $\mathrm{F}(\mathrm{r}, \theta)$ da fonte de ${ }^{192} \mathrm{Ir}$ em um meio equivalente à água; Comparar os valores de $\mathrm{F}(\mathrm{r}, \theta)$ utilizados pelo sistema de planejamento em braquiterapia, BrachyVision, com os obtidos experimentalmente. Métodos: Foi utilizada a unidade GammaMed, a qual utiliza fonte de ${ }^{192}$ Ir. No BrachyVision, foi otimizado um planejamento e um filme foi exposto, gerando distribuições de dose. A densidade ótica foi convertida para dose, utilizando o software VeriSoft. Em seguida, foi calculada $\mathrm{F}(\mathrm{r}, \theta)$ para diversos ângulos e distâncias. Os valores obtidos foram comparados com os do BrachyVision. Resultados: Obteve-se a anisotropia para distâncias entre $0,8 \mathrm{~cm}$ e $2,5 \mathrm{~cm}$ e ângulos entre $0^{\circ}$ e $90^{\circ}$. Para distâncias e ângulos pequenos, os valores calculados e utilizados pelo BrachyVision apresentaram grande diferença por estas posiçôes estarem próximas à fonte. Para outras situaçōes, as diferenças foram menores que 9\%, portanto, aceitáveis segundo TECDOC1151. Conclusões: Através de ferramentas simples pôde-se determinar a anisotropia de uma fonte, permitindo verificar os parâmetros utilizados pelo sistema de planejamento.

63

\section{Estudo comparativo nas técnicas de} tratamentos radioterápicos convencional e conformacional em pacientes com neoplasia gástrica

Santos EM, Najas RMFX, Pinheiro AKDC, Menezes NA, Telles LFK, Gouveia NM Liga Norte Rio-grandense Contra o Câncer (LNRCC) - (RN)

Introdução: No Brasil, o câncer gástrico ainda representa importante causa de óbito, colocando-se entre as cinco localizaçóes mais comuns de neoplasia primária em ambos os sexos. Avaliar a homogeneidade de dose nas diferentes técnicas de tratamento, comparando os planejamentos convencionais (2D) e conformacionais (3D). Estudo retrospectivo, realizado no Serviço de Radioterapia da LNRCC. Foram selecionados, aleatoriamente, 10 pacientes com neoplasia gástrica, operados e admitidos para tratamento radioterápico conformacional, conforme rotina do Serviço (45Gy em 3 ou 4 campos). Realizou-se um planejamento bidimensional em cada paciente. Usando imagem radiográfica do sistema de planejamento 3D (DRR), com a projeção somente dos rins, desenhou-se um planejamento, paralelo e oposto, conforme regras do planejamento $2 \mathrm{D}$ para estômago. Campos com o limite cranial T10, caudal L3, lateral esquerda até $3 / 4$ do hemi-abdome esquerdo e na lateral direita do hemiabdome direito, adicionando os devidos blocos. Usando o sistema de planejamento 3D, obteve-se um histograma de dose vs volume de cada paciente. Quanto à cobertura de dose no CTV, somente dois pacientes receberiam menos do que $95 \%$ da dose em $95 \%$ do volume. Contudo, um paciente receberia $30 \%$ da dose em $95 \%$ do volume se tratado com planejamento 2D. A dose modal no CTV foi maior do que $45 \mathrm{~Gy} \mathrm{em}$ todos os pacientes. A dose limite no fígado foi respeitada em todos os pacientes. A dose em medula foi maior do que 45Gy nos dez pacientes planejados de maneira convencional.

Texto truncado.

62

\section{Radioterapia em tumores sincrônicos de} bexiga e próstata: comparação entre planejamento conformacional e radioterapia com intensidade modulada (IMRT)

\section{Morais DCR, Silva JHC, Erlich F, Bezerra ML, Batista DVS, Viegas CM, Araújo CM Instituto Nacional de Câncer - Rio de Janeiro - (RJ)}

Introdução: Achado incidental de carcinoma de próstata (CaProst) em pacientes com câncer de bexiga (CaBex) é variável na literatura médica. A necessidade de altas doses em diferentes volumes, aliada à proximidade com determinados órgãos de risco, aumenta a utilidade do IMRT nesses casos. Objetivo: Comparar a radioterapia conformacional (RxTConf) com IMRT em paciente com CaBex concomitante a CaProst. Métodos: Realizada TC para planejamento em paciente com CaProst e CaBex. Os volumes-alvo (CTV) foram CTVCaProst - próstata e vesículas seminais (Prost+VS), CTVCaBex - bexiga e linfonodos pélvicos (LNPelv). Reto, intestinos e fêmures foram órgãos de risco. RxTConf planejada em 3 etapas: 50Gy/25 fraçôes sobre pelve; 16Gy/8 frações sobre bexiga e Prost+VS e 6Gy/3 fraçōes sobre Prost+VS (doses finais em Prost+VS: 72Gy, em bexiga: 66Gy e LNPelv: 50Gy). Planejamento de IMRT com 07 campos em fase única prescritos: $58,1 \mathrm{~Gy} / 36$ fraçôes sobre LNPelv; 68,4Gy/36 fraçôes sobre bexiga (considerando-se cálculos de dose biologicamente efetiva) e $72 \mathrm{~Gy} / 36$ fraçôes sobre Prost+VS. Resultados: Cobertura nos CTV equivalente com menores doses nos órgãos de risco com IMRT. Conclusão: Radioterapia deve ser individualizada e IMRT confere distribuição de dose adequada, minimizando doses nos tecidos críticos, quando comparada à RxTConf. 


\section{Avaliação das alterações no desenvolvimento dentário após irradiação em crianças com rabdomiossarcoma [RMS] de cabeça e pescoço [CP]}

\author{
D `Aiuto VM', Viégas CMP², Antunes HS', Pinheiro $\mathrm{CT}^{1}$, Mello RCR \\ Magalhães $\mathrm{D}^{2}$, Araújo CMM² \\ 'Seção de Estômato-Odontologia e Prótese, ${ }^{2}$ Radioterapia e ${ }^{3}$ Medicina Nuclear do \\ Instituto Nacional de Câncer - Rio de Janeiro - (RJ)
}

Introdução: RMS é um tumor pediátrico raro que acomete crianças em idade de formação dentária, sendo CP o sítio primário mais afetado. A radioterapia (RT) é freqüentemente empregada, porém há poucos relatos sobre as alteraçóes tardias no desenvolvimento dentário pós-tratamento. Objetivo: Descrever as principais alteraçōes dentárias pós-RT de RMS de CP em crianças. Métodos: De junho de 2005 a janeiro de 2006, foram avaliadas através de estudo radiográfico panorâmico de mandíbula e maxila 9 crianças ( 7 meninos e 2 meninas) submetidas à RT, com idade inferior a 5 anos na ocasião do tratamento. Foram identificadas as principais alteraçôes e elementos dentários mais envolvidos. A faixa etária no momento do estudo foi de 10 a 12 anos. Resultados: As crianças não foram operadas; foram utilizados em todos os casos adriamicina, actinomicina, ciclofosfamida e vincristina. Ossos zigomáticos ou mandibular foram parcial ou totalmente incluídos no campo de tratamento em $55,5 \%$ e $77,7 \%$ dos casos, respectivamente. O feixe mais utilizado foi Cobalto- 60 $(88,8 \%)$, e a dose mais freqüentemente empregada, $5040 \mathrm{cGy} / 28$ fraçôes. Estudaram-se no total 241 elementos dentários, sendo encontradas 148 anomalias (61\% dos elementos), sendo a mais comum, encurtamento radicular ( $29,72 \%$ dos casos); e o elemento mais envolvido, primeiro molar inferior esquerdo, com a proporção de 16 elementos alterados para cada normal. Conclusões: Crianças em idade de pré-formação dentária com RMS de CP submetidas à RT necessitam de avaliação odontológica rigorosa precoce e tardia, além de seguimento prolongado, visto que alteraçóes ocorrem em mais da metade dos elementos dentários, dentro de ou próximo ao campo irradiado.

65

\section{Linfoma cutâneo: irradiação de toda a pele}

Esteves $\mathrm{SCB}^{1,2}$, Oliveira ACZ1, Cunha MO', Gomes $\mathrm{H}^{2}$, Tagawa E² ${ }^{1}$ Caism-Unicamp, ${ }^{2}$ Hospital São Joaquim - Benefeciência Portuguesa São Paulo São Paulo - (SP)

Introdução: A incidência dos linfomas cutâneos, em particular da micose fungóide, é muito rara. As lesões cutâneas causam desconforto, e a radioterapia de toda a pele, com o uso de feixe de elétrons, é o agente isolado mais eficaz no tratamento da micose fungóide. Métodos: No período de março de 1996 a agosto de 2005, 54 pacientes foram submetidos à radiação de toda a pele com feixe de elétrons, para o tratamento da micose fungóide. O tempo de seguimento variou de 6 a 136 meses. A técnica utilizada foi a de Stanford modificada, com doses de 30Gy a 36Gy. Resultados: A taxa de controle esteve diretamente relacionada ao estádio clínico da doença. Estádio Ia $100 \%$; estádio Ib $70 \%$; estádio II $58 \%$; estádio III 20\%; estádio IV 0\%. Dez pacientes foram irradiados pela segunda vez, e dois receberam tratamento de toda a pele em três oportunidades. Destes (12), 5 estão sem evidências de doença. A toxicidade cutânea predominante observada foi de graus I e II com alguns episódios de descamação úmida (10\%) controlada sem dificuldades. Conclusóes: Pode-se concluir que a radiação de toda a pele com feixe de elétrons é uma técnica de tratamento consagrada, na experiência mundial, para os linfomas cutâneos de células $T$. Nos estádios iniciais (I e II), a probabilidade de controle da doença é elevada.

\section{Estudo sobre a reutilização do cerrobend}

Oliveira JLP1,2, , Leite $\mathrm{ML}^{2}$, Viégas CCB $^{3}$, Padilha Filho LG ${ }^{1,2}$, Canary PCV' 'Universidade Federal do Rio de Janeiro (HUCFF), ${ }^{2}$ Fundação Téenico Educacional Souza Marques - (RJ), ${ }^{3}$ Instituto Nacional de Câncer - Rio de Janeiro - (RJ)

Introdução: Cerrobend é uma liga metálica utilizada na colimação de campos em teleterapia. Objetivos: Avaliar amostras após consecutivas reutilizações, comparando-se a transmissividade em função da densidade e do peso, através de densitometria ótica e de leituras com câmara de ionização. Métodos: Foram confeccionados quatro blocos retangulares. $\mathrm{O}$ primeiro de liga derretida uma vez. No segundo, cerrobend fundido quinze vezes. $\mathrm{O}$ terceiro, com a mesma liga do primeiro. No quarto, apenas cerrobend oxidado. Os blocos foram radiografados lateralmente com irídio, a densidade verificada com densitômetro. Obteve-se transmissividade realizandose medidas no ar com fótons de 6MV. Para verificar o peso, utilizouse balança digital. Resultados: A densitometria comparativa revelou: os dois primeiros blocos têm maior densidade central. $\mathrm{O}$ de cerrobend reutilizado é mais denso em grande parte do terço superior. Houve diferença no peso de $3,8 \%$, suas transmissividades foram iguais. Para o terceiro e quarto blocos, o composto de borra apresentou perda de $17,25 \%$ e aumento de $15 \%$ na transmissividade. Não foi encontrada descontinuidade nos blocos radiografados. Conclusóes: Apesar de oxidar na fusão, retirando-se as borras o cerrobend pode ser reutilizado seguramente por quinze vezes, pois sua transmissão é idêntica ao do cerrobend fundido uma vez. Os blocos têm distribuição de densidades semelhantes, maior no centro e menor nas laterais e bases.

66

\section{Radiocirurgia com acelerador linear:}

experiência do Hospital Araújo Jorge de 158 pacientes utilizando Sistema de Microlâminas Brainlab ${ }^{\circledR}$

Paiva JT, Santos Neto GP, Bezerril CF, Zaccariotti VA, Arruda JB, Goulart FB Hospital Araújo Jorge - Associação de Combate ao Câncer em Goiás - (GO)

Introdução: Radiocirurgias com aceleradores lineares vêm sendo empregadas há décadas, com muito sucesso, no tratamento de várias doenças neurológicas, principalmente as neoplasias intracranianas. Os resultados obtidos com esta técnica têm se tornado cada vez mais expressivos e reconhecidos. Objetivos: Apresentar e avaliar a experiência em radiocirurgia no Hospital Araújo Jorge através do emprego de cones e microlâminas (M3) em acelerador linear. Métodos: Foram analisados retrospectivamente todos os casos tratados entre fevereiro de 2000 a julho de 2006 com radiocirurgia no Hospital Araújo Jorge. Foram utilizados no tratamento um acelerador linear 600C $\operatorname{Varian}^{\circledR}$ e acessórios para radiocirurgia BrainLab $b^{\circledR}$; optando-se por cones ou microlâminas de acordo com a geometria de cada lesão. Resultados: Avaliou-se um total de 158 pacientes com soma final 216 lesōes tratadas através desse método. Destas, 194 lesōes com M3 e 22 com cones. A resposta ao tratamento foi muito satisfatória, atingindo-se resposta terapêutica local objetiva em $95 \%$ das lesões. A sobrevida média variou de acordo com o tipo histológico das lesóes. Todos os procedimentos foram realizados sem intercorrências. As complicações agudas e tardias ocorreram em 5\% dos pacientes (8/158), sendo todas de graus I e II. Conclusóes: Conclui-se que se trata de um método confiável, com baixo risco de complicaçôes e muito eficaz quando bem indicado. 


\section{Objeto simulador (Phantom) antropomórfico} para o controle de qualidade de radiocirurgia estereotáxica

\author{
Soboll DS, Schelin HR \\ Programa de Pós-Graduação em Engenharia Elétrica e Informática Industrial (CPGEI)- \\ Universidade Tecnológica Federal do Paraná - UTFPR - Curitiba - (PR)
}

Introdução: A radiocirurgia estereotáxica trata lesōes cerebrais pequenas com doses grandes de radiação ionizante, o que exige rigoroso controle da qualidade (CQ) de cada etapa. Objetivos: Apresentar o phantom para CQ de radiocirurgia desenvolvido na UTFPR. Métodos: Foram moldadas placas termoplásticas PET transparentes em forma de cabeça humana. Uma barra de polietileno UHMW 1900 suporta quatro objetos de referência e teste. Uma esfera de PVC de baixa densidade representa o olho direito. $\mathrm{O}$ phantom foi preenchido com água e submetido às etapas típicas de uma radiocirurgia. Comprimentos e volumes medidos foram comparados com os fornecidos pelo sistema de planejamento. Durante a irradiaçāo, fizeram-se imagens em filmes de Raios-X. Resultados: $\mathrm{O}$ custo do phantom foi de menos de mil reais. A sua massa é de $5,0 \mathrm{~kg}$ (com água) e a superfície externa não fletiu nos exames. As medidas craniais externas representam dimensōes humanas. Não ocorreram artefatos produzidos pelo phantom nas imagens. Os volumes dos objetos de referência e o teste do sistema de planejamento foram corretos quando se utilizaram as janelas de visualização adequadas. A reconstrução em $3 \mathrm{D}$, a fusão de imagens, a exportação dos contornos e a posição dos arcos foram avaliadas e aprovadas. $\mathrm{O}$ erro de posicionamento do isocentro foi de $1 \mathrm{~mm}$. Conclusóes: $\mathrm{O}$ objeto simulador antropomórfico é adequado para o CQ de radiocirurgia. Atualmente ele está em aprimoramento dosimétrico para desenvolver um programa de avaliação postal com TLD em conjunto com o PQRT/ INCA.

69

Resultados preliminares do uso de heterojunções de polianilina-silício em dosimetria

Riedtmann RWW', Schelin HR', Soboll DS', Gonçalves VD², Martins Jr LB ${ }^{3}$ 'Programa de Pós-Graduação em Engenharia Elétrica e Informática Industrial (CPGEI) Universidade Tecnológica Federal do Paraná UTFPR - Curitiba - (PR), '2Departamento de Física Médica, Oncoville - Curitiba - (PR), ${ }^{3}$ Radioterapia do Hospital Municipal São José - Joinville - (SC)

Introdução: Heterojunçôes de polianilina-silício são filmes finos de polianilina depositados sobre substrato de silício. Quando recebem radiaçáo ionizante, alteram suas características elétricas e indicam a dose recebida. Objetivo: Apresentar resultados preliminares dos dispositivos irradiados. Métodos: Foi depositada polianilina com $40 \mathrm{~nm}$ de espessura pelo método de spin coating sobre um substrato de Si (100). A polianilina foi dopada e se evaporaram contatos de alumínio sobre o filme. Cada placa quadrada de Si tem $1 \mathrm{~cm}$ de lado, com espessura $1 \mathrm{~mm}$ e tem de 4 a 5 contatos. Assim, uma placa são 4 ou 5 dispositivos reunidos. Em um acelerador linear Clinac 2100 SC foram aplicados 2Gy e 50Gy com fótons, $6 \mathrm{MV}$ e elétrons, $9 \mathrm{MV}$. Com ${ }^{60} \mathrm{Co}$ aplicaram-se $50 \mathrm{~Gy}$, 750 Gy e 1500 Gy. Para cada aplicação utilizaram-se 3 placas. Foi levantada a curva de tensão versus corrente dos dispositivos, utilizando-se uma fonte de tensão e um multímetro programáveis. Resultados: A variação da leitura apresentou resposta linear, com valores de corrente direta acima do dobro para doses de 750Gy e $1500 \mathrm{~Gy}$, comparando com dispositivos não irradiados. Em baixas doses, a sensibilidade não foi linear e nem reprodutível. $O$ processo é destrutivo, entretanto, a produção apresenta baixo custo e a instrumentação de leitura é simples se comparada com a de TLD. Conclusōes: A pequena área de um dispositivo, o baixo custo, a simplicidade de leitura e os primeiros resultados para altas doses incentivam a prosseguir para aprimorar os dosímetros e utilizá-los em baixas doses da faixa clínica.

71

\section{Avaliação postal com TLD para a radiocirurgia}

\author{
Soboll DS, Schelin HR \\ Programa de Pós-Graduação em Engenharia Elétrica e Informática Industrial (CPGEI) \\ - Universidade Tecnológica Federal do Paraná UTFPR - Curitiba - (PR)
}

Introdução: A avaliação postal é uma maneira independente de validar a calibraçăo de feixes de radioterapia para prevenir acidentes com radiação e evitar doses incorretas, utilizando dosímetros termoluminescentes (TLD). A radiocirurgia ainda não foi contemplada por um programa de avaliação postal como os oferecidos pela Agência Internacional de Energia Atômica (AIEA) e, no Brasil, pelo Programa de Qualidade em Radioterapia do Instituto Nacional de Câncer (PQRT/INCA). Objetivo: Apresentar o desenvolvimento da avaliação postal com TLD para a radiocirurgia, em andamento na UTFPR. Métodos: Está em aprimoramento dosimétrico com TLD, um objeto simulador (phantom) antropomórfico de cabeça. Em uma avaliação postal típica, a clínica receberá o phantom e o preencherá com água para realizar as etapas de uma radiocirurgia. Os TLD serão inseridos no phantom para a irradiação no aparelho de tratamento. Atualmente somente o RPC (Radiation Physics Center), no Hospital MD Anderson, nos Estados Unidos, oferece um serviço de avaliação postal para radiocirurgia, pelo qual se cobram US\$450. Uma visita ao RPC deverá trazer informaçôes sobre a experiência com essa técnica, que auxiliarão o desenvolvimento do programa postal. Conclusōes: O resultado do desenvolvimento da avaliação postal tem uma aplicação prática relevante para o panorama nacional brasileiro, pois já são em torno de 20 as clínicas que oferecem radiocirurgia no país. É necessário desenvolver um programa de avaliação postal de radiocirurgia. $\mathrm{O}$ resultado será o aumento da qualidade e da segurança dos tratamentos.

70

\section{Desenvolvimento de um plugin para planejamento computadorizado de tratamentos com campos de radiação irregulares}

Caron RF, Murta Junior LO, Nicolucci P Departamento de Física e Matemática - USP/Ribeirão Preto - (SP)

Neste trabalho foi desenvolvido um plugin de processamento de imagens para o cálculo automático do campo quadrado-equivalente a um campo de radiação irregular. O plugin foi desenvolvido em linguagem Java, para o aplicativo ImageJ, de domínio público, visando à sua portabilidade e possibilitando seu uso em qualquer serviço de Radioterapia sem custos adicionais. Dois algoritmos de cálculo foram implementados: o primeiro é baseado na determinação da proporção entre a área e o perímetro da porção livre do campo (método de Sterling) e o segundo é baseado no cômputo separado das componentes primária e secundária de dose no ponto de cálculo de dose (método de Clarkson). Nos dois algoritmos, um método semi-automático foi implementado, sendo que o usuário deve marcar com o mouse apenas o centro do campo - os limites do campo e as regiōes de blindagens ou campo livre são automaticamente reconhecidos. Para teste do plugin, os resultados de campos quadrado-equivalentes de planejamentos radioterápicos, obtidos através de planejamento computadorizado utilizando o sistema de planejamento radioterápico InterSoft, foram comparados com os obtidos através do uso do plugin. Os resultados obtidos para os planejamentos realizados mostraram uma diferença significativa (de até $28 \%$ ) entre os campos quadrado-equivalentes calculados com os dois diferentes algoritmos. Na comparação entre o plugin (utilizando o algoritmo Clarkson) e o sistema de planejamento, foi encontrada uma concordância melhor do que $96,4 \%$. 


\section{Determinação de distribuições de doses radioterápicas através de dosimetria} termoluminescente e simulação Monte Carlo

Gonçalves DM, Tessone VL, Moraes CV, Nicolucci P Departamento de Física e Matemática - USP/Ribeirão Preto - (SP)

Dosímetros termoluminescentes possuem características convenientes para utilização em dosimetria in vivo em pacientes radioterápicos ou para a avaliação da acurácia de sistemas de planejamento radioterápico. A resposta desses detectores, entretanto, depende fortemente das características espectrais do campo de radiação e das condiçóes de irradiação, exigindo um processo de calibração minucioso. A simulação Monte Carlo pode fornecer um meio eficaz para a interpolação e a extrapolação de dados experimentais obtidos com esses detectores em campos radioterápicos. Neste trabalho, dosímetros termoluminescentes de fluoreto de lítio (LiF100) foram utilizados para a determinação da PDP em um objeto simulador homogêneo, e a comparação desses dados com os dados simulados pelo método Monte Carlo permitiram avaliar o processo de calibração desses detectores para a obtenção desse parâmetro dosimétrico. Os detectores foram, então, utilizados nas cavidades internas de um objeto simulador antropomórfico para a avaliação das distribuiçốes de doses obtidas em tratamentos radioterápicos. Nessa etapa, a simulação Monte Carlo foi utilizada para a interpolação de valores de dose absorvida entre posiçōes de dosímetros sucessivos, permitindo a comparação das distribuições de dose planejada e recebida em um tratamento radioterápico. Os resultados obtidos mostram que a acurácia na determinação de distribuiçôes de dose radioterápicas obtidas com dosímetros termoluminescentes é significativamente influenciada pelo processo de calibração dos mesmos em função do espectro de radiação em diferentes profundidades do material irradiado.

Perfis de campos filtrados para feixes de fótons de 6MV medidos com o Dosímetro Fricke Gel modificado

Oliveira LN', Guzmán $\mathrm{CS}^{1}$, , Cavalcante F', Almeida A', Almeida $\mathrm{CE}^{2}$ 'Departamento de Física e Matemática, FFCLRP, Universidade de São Paulo - (SP), 2Laboratorio de Ciências Radiológicas, Universidade do Estado do Rio de Janeiro - (RJ)

O dosímetro Fricke Gel Modificado (FXG) foi utilizado para medidas dos perfis de campos, o qual consiste de um gel contendo íons de Fe (II) que transformam em Fe (III), quando irradiados. Da variação da concentração do $\mathrm{Fe}$ (III), inferida da medida da absorbância (através da fotoespectrometria), a dose absorvida pela amostra pode ser obtida. Para este estudo, cubetas de acrílico preenchidas com o FXG foram utilizadas e essas foram inseridas num objeto simulador (OS). Sobre este, foi adicionada outra placa com as mesmas dimensões, mas com uma espessura de $15 \mathrm{~mm}$ devido ao equilíbrio eletrônico (dmáx) e abaixo foram adicionadas placas para evitar o retroespalhamento. O conjunto FXG + OS foi irradiado com fótons de 6MV do LINAC (Siemens/Mevatron), dose absorvida de $2 \mathrm{~Gy}$, distância fonte superfície (DFS) de $100 \mathrm{~cm}$, campos de $10 \mathrm{~cm}^{2} \times 10 \mathrm{~cm}^{2}, 15 \mathrm{~cm}^{2} \times 15 \mathrm{~cm}^{2}$ e $20 \mathrm{~cm}^{2} \times 20 \mathrm{~cm}^{2}$ nas profundidades de: $1,5 \mathrm{~cm} ; 2,5 \mathrm{~cm} ; 9 \mathrm{~cm} ; 10 \mathrm{~cm} ; 20 \mathrm{~cm}$ e $21 \mathrm{~cm}$. Pelas análises dos dados obtidos das leituras, foi possível encontrar uma diferença percentual máxima de $2 \%$ entre FXG e Monte Carlo e de $\cong 1 \%$ com os demais dosímetros: câmara de ionização, diodo e filmes. Dos dados obtidos, pode-se concluir que o FXG também pode ser utilizado como um sistema dosimétrico alternativo, para medidas dos perfis de campos filtrados.
Alças intestinais na proximidade do volume de planejamento de radioterapia conformacional de câncer de próstata: uma inclusão subestimada

Viégas CMP, Sbaraini P, Gonçalves M, Araujo CMM Centro Radioterápico Gávea - Rio de Janeiro - (RJ)

Introdução: São órgãos de risco em radioterapia conformacional (RTConf) de câncer de próstata (CaProst): reto, bexiga, fêmures e bulbo peniano. Há poucos relatos da incidência de inclusão de alças intestinais (AçIntest) no volume-alvo de planejamento (PTV), bem como o registro de dosagens. Objetivo: Relatar a incidência de inclusão de AçIntest no PTV e mensurar dose recebida em RTConf de pacientes com CaProst. Métodos: Foram avaliados os planejamentos de RTConf de 17 pacientes. O volume-alvo clínico (CTV) consistiu da próstata e vesículas seminais (P+VS). PTV correspondeu ao CTV expandido em $10 \mathrm{~mm}$ tridimensionalmente, exceto próximo ao reto, com expansão de $7 \mathrm{~mm}$. Todos os pacientes foram planejados para receber $72 \mathrm{~Gy} / 36$ fraçōes (sistema Prowess $®)$. Alças intestinais (ceco, sigmóide, descendente e delgado) foram delineadas, quando visíveis, na tomografia computadorizada, até a junção L5/S1. A presença de AçIntest na proximidade do PTV foi verificada e as doses recebidas foram mensuradas. Foram determinados os volumes (cc) de AçIntest que recebiam 45Gy (V45), 40Gy (V40) e 35Gy (V35), além das doses máximas pontuais detectadas. Resultados: Proximidade de AçIntest ao PTV foi identificada em $100 \%$ dos casos. Volumes médios de AçIntest determinados para V45, V40 e V35 foram respectivamente de 7,54cc (046,7), 13,95cc (0-59,6) e 21,34cc (0-82,3). Em média, doses máximas pontuais foram de 60,09Gy $(33,27-76,77)$. Conclusão: AçIntest foram sistematicamente identificadas próximas ao PTV e ocasionalmente podem receber sobredosagem.

Texto truncado.

74

Determinação das doses administradas em irradiação de corpo inteiro e estudo de uma metodologia para dosimetria in vivo em radioterapia

Alva M, Nicolucci P

Departamento de Física e Matemática, Faculdade de Filosofia Ciências e Letras de Ribeirão Preto (FFCLRP/DFM/USP), Ribeirão Preto - (SP)

A avaliação da conformidade entre a dose prescrita e a dose administrada em tratamentos radioterápicos é fundamental para garantir a eficácia do tratamento. Especialmente em irradiação de corpo inteiro, a alta toxicidade do tratamento requer um controle rigoroso das doses administradas, fazendo com que um programa de verificação do tratamento através de dosimetria in vivo seja imprescindível. Neste trabalho, cavidades de um objeto simulador antropomórfico foram preenchidas com detectores termoluminescentes de fluoreto de lítio (TLD-100) devidamente calibrados em feixes de uma unidade de cobaltoterapia. Durante a irradiação do objeto simulador, diodos de silício foram posicionados nas superfícies de entrada e de saída do objeto simulador. Após a irradiação, as pastilhas termoluminescentes foram lidas e as doses em pontos de referência foram comparadas com as doses planejadas. A leitura dos diodos, em comparação com as doses determinadas com os detectores termoluminescentes, proporcionou um meio de avaliação da viabilidade do uso desses detectores em dosimetria in vivo em irradiação de corpo inteiro. Os resultados preliminares deste trabalho indicam que diferenças significativas entre as doses prescrita e administrada ao paciente podem ser encontradas em irradiação de corpo inteiro. Em irradiaçóes iniciais, uma diferença de até $24 \%$ foi encontrada, para o mediastino, entre a dose prescrita e administrada.

76 


\section{Medida de dose de nêutrons em labirintos de salas de aceleradores lineares médicos}

Rivera JC', Falcão RC ${ }^{1}, 2$, Almeida CE

'Laboratório de Ciências Radiológicas - LCR/UERJ - Rio de Janeiro - (RJ),

${ }^{2}$ Comissão Nacional de Energia Nuclear - Rio de Janeiro - (RJ)

Atualmente, equipamentos de teleterapia com césio e cobalto vêm sendo substituídos por aceleradores lineares. A energia máxima de fótons nessas máquinas pode variar de $4 \mathrm{MV}$ a $25 \mathrm{MV}$, e uma das grandes vantagens desses equipamentos, sob o ponto de vista de radioproteçáo, é de não possuírem fonte radioativa incorporada. Aceleradores lineares de alta energia (E>10MV) oferecem algumas vantagens quando comparados com os de energia mais baixa: sendo o feixe mais penetrante, a dose na pele é menor, assim como é a dose espalhada nos tecidos vizinhos ao volume-alvo. Por outro lado, a contaminaçáo do feixe terapêutico por nêutrons gerados por esses fótons de alta energia tornou-se um problema adicional de proteção ao paciente e a trabalhadores ocupacionalmente expostos. As paredes das salas de tratamento são projetadas para atenuar os feixes primário e secundário de raios-X, e essa blindagem é em geral adequada para atenuar nêutrons. No entanto, esses nêutrons são espalhados através do labirinto da sala, e podem resultar num risco radiológico na porta de entrada, normalmente uma área de alto fator de ocupação numa instalação de radioterapia.

Neste trabalho, são apresentados os dados preliminares de medidas de equivalentes de dose de nêutrons, feitas ao longo de labirintos de salas de radioterapia, utilizando detetores de bolhas. Foram investigadas inicialmente quatro intituiçóes, sendo três no Rio de Janeiro e uma em S. Paulo, onde estavam instalados um total de sete aceleradores, cujas energias variavam de $10 \mathrm{MV}$ a $18 \mathrm{MV}$.

Texto truncado.

\section{Simulação da distribuição de doses absorvidas pelo coração de ratos tipo Wistar utilizando o código MCNP}

\author{
Chung $\mathrm{CE}^{12,3}$, de Amorim $\mathrm{A}^{5}$, HoffG ${ }^{4}$, Balthar MC ${ }^{5}$, de Almeida $\mathrm{CE}^{1}$ \\ 'Laboratório de Ciências Radiológicas, LCR/UER - Rio de Janeiro (R), ${ }^{2}$ Facultad de C. Físicas, \\ UNMSM, Lima (Peru), ${ }^{3}$ Facultad de C. Físicas, UNI, Lima (Peru) 'Faculdade de Física, GSCFM./ \\ PUCRGS. Porto Alegre (RS), ${ }^{5}$ Centro Tecnológico do Exército - CTEx - Rio de Janeiro (R)
}

Introdução: Este trabalho faz parte de um projeto multidisciplinar que investiga vários aspectos relacionados à radiotoxicidade do coração, devido à sua exposição durante a irradiação da mama esquerda. Objetivos: Pretende-se estudar a distribuição de dose no coração (além, de outros órgãos vizinhos) nos ratos irradiados, a fim de permitir uma melhor correlação entre a dose absorvida e o efeito nos tecidos analisados. Métodos: A dose foi obtida através de simulaçōes com o código MCNP simulando-se espectros de fótons de energia nominal de $6 \mathrm{MV}$ em aceleradores lineais. Para a validação da metodologia, um fantoma de água de $20 \times 20 \times 20 \mathrm{~cm}^{3}$ foi feito, e dividido em voxels de $0,5 \times 0,5 \times 0,5 \mathrm{~cm}^{3}$, acoplado ao MCNP através da técnica de estruturas repetidas, para a obtenção das curvas de isodoses. Estas curvas foram comparadas com isodoses experimentais. Posteriormente, utilizando um conjunto de cortes tomográficos de um casal de ratos, a segmentação foi realizada e depois a voxelização de $0,5 \times 0,5 \times 1 \mathrm{~mm}^{3}$. Logo foi realizada a simulação da irradiação, utilizando a mesma técnica de estruturas repetidas que se utilizou no fantoma. As distribuiçôes de doses obtidas foram comparadas com os cálculos realizados por um sistema TPS. Resultados: A metodologia adotada possibilitou o cálculo da distribuição de dose não só no coração, mas também em órgãos considerados críticos, como pulmão e medula. Os resultados obtidos serão utilizados para a avaliação e análise da curva de dose resposta dos tecidos irradiados no coração dos pacientes com câncer de mama.

79

\section{Calibração de dosímetros TL em feixes de elétrons aplicados à radioterapia}

Nunes MG, Campos LL

Instituto de Pesquisas Energéticas e Nucleares - IPEN-CNEN/SP- São Paulo - (SP)

Este trabalho visa a comparar a resposta TL dos dosímetros de $\mathrm{CaSO}_{4}: \mathrm{Dy}$ (IPEN) e de LiF:Mg,Ti (TLD-100, Harshaw) a feixes de elétrons de $4 \mathrm{MeV}, 6 \mathrm{MeV}, 9 \mathrm{MeV}, 12 \mathrm{MeV}$ e $15 \mathrm{MeV}$ utilizando objetos simuladores de Água Sólida RW3 e de Lucite. Dosímetros previamente selecionados foram posicionados sobre aproximadamente $5 \mathrm{~g} \cdot \mathrm{cm}^{2}$ do material do objeto simulador na profundidade de máxima ionização dos feixes e irradiados com doses de 1cGy a 15Gy para o levantamento das curvas de calibração para elétrons de $4 \mathrm{MeV}$ e doses de 0,10Gy e 2,50Gy para a avaliaçấo das respostas TL às demais energias do feixe. A leitura TL foi feita 36 horas após a irradiação em um leitor QS 3500 (Harshaw), sendo que cada ponto representa a média das leituras de cinco dosímetros de sensibilidades próximas, subtraída a média das leituras de cinco dosímetros nãoirradiados. As curvas de dose-resposta obtidas para o feixe de elétrons de $4 \mathrm{MeV}$ apresentam comportamento linear no intervalo de dose de $0,01 \mathrm{~Gy}$ a 2,5Gy, apresentando uma clara tendência à supralinearidade a partir desta dose, independentemente do dosímetro ou do objeto simulador empregados. Embora o CaSO4:Dy seja de $16 \pm 10$ a $21 \pm 5$ vezes mais sensivel que o $\mathrm{LiF}: \mathrm{Mg}, \mathrm{Ti}$, ambos os materiais são mais sensíveis às energias consideradas em Água Sólida que em Lucite e suas dependências energéticas apresentam o mesmo comportamento nos dois objetos simuladores empregados, de modo que, nas condiçóes estudadas, o LiF:Mg,Ti pode ser substituído pelo dosímetro nacional com um ganho considerável na sensibilidade. 